\title{
Synthesis and Characterization of a Dicationic Dihydrogen Complex of Iridium with a Bis-Carbene Ligand Set
}

\author{
Matthias Vogt, Vincent Pons and D. Michael Heinekey* \\ Department of Chemistry, University of Washington, Box 351700 \\ Seattle, WA 98195-1700
}

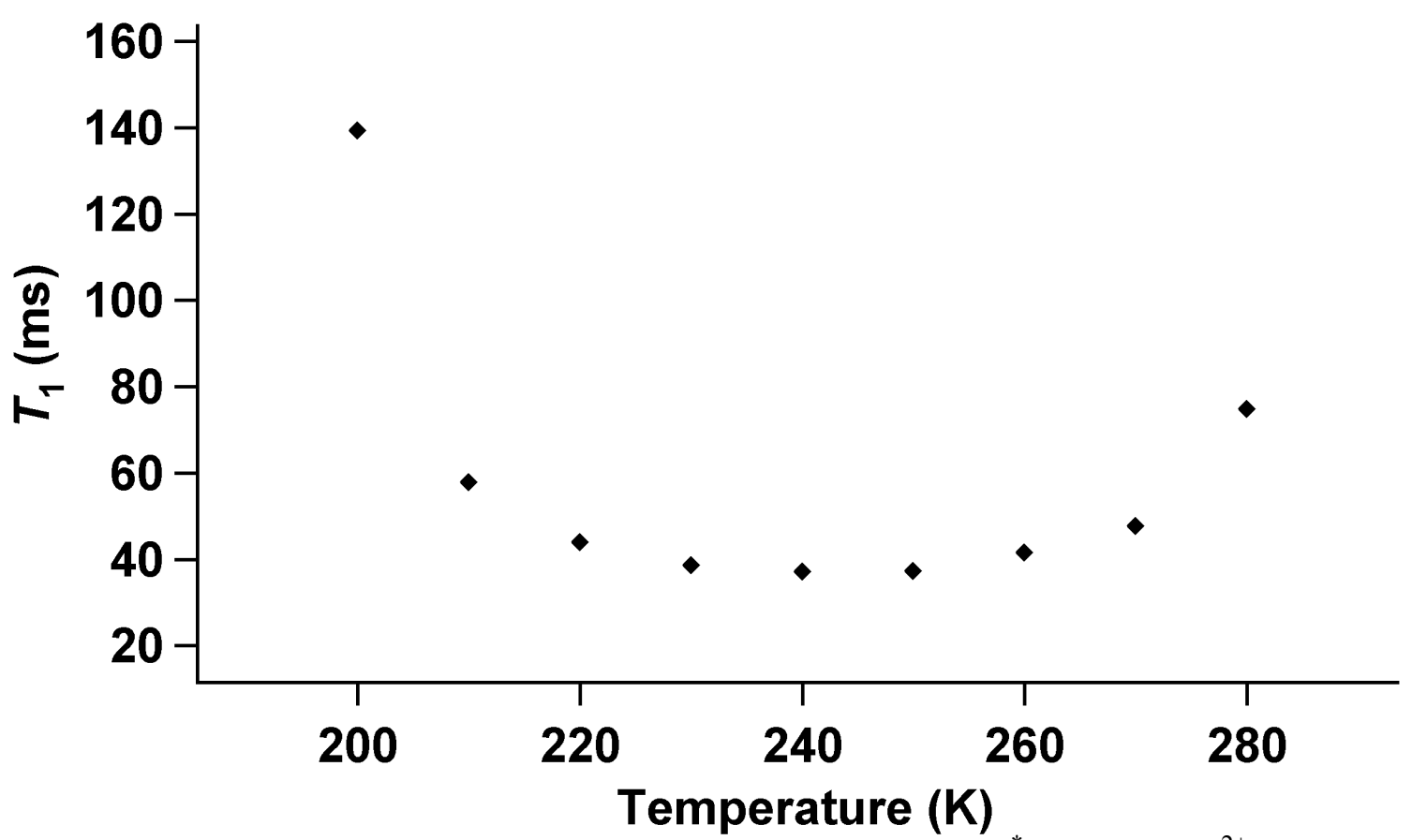

Variable temperature studies of the dihydrogen resonance of $\left[\mathrm{Cp}{ }^{*} \operatorname{Ir}(\mathrm{C}-\mathrm{C})\left(\mathrm{H}_{2}\right)\right]^{2+}\left(\mathrm{CD}_{2} \mathrm{Cl}_{2}, 750\right.$ $\mathrm{MHz}$ ). 
X-ray Structure of $\left[\mathbf{C p}^{*} \operatorname{Ir}(\mathbf{C}-\mathbf{C}) \mathbf{C I}\right]\left[\mathbf{P F}_{\mathbf{6}}\right]$. Yellow crystals suitable for X-ray diffraction were obtained by diffusion of $\mathrm{Et}_{2} \mathrm{O}$ into a solution of $\left[\mathrm{Cp}{ }^{*} \mathrm{Ir}(\mathrm{C}-\mathrm{C}) \mathrm{Cl}\right]\left[\mathrm{PF}_{6}\right]$ in $\mathrm{CH}_{2} \mathrm{Cl}_{2}$ and mounted on glass capillaries in oil. Diffraction measurements were made on crystal fragment of dimensions $0.24 \times 0.24 \times 0.24 \mathrm{~mm}$ in a nitrogen stream at $130 \mathrm{~K}$ on a Nonius KappaCCD diffractometer using graphite-monochromated radiation $(\lambda=0.71073 \AA)$. Crystal-to-detector distance was 30 $\mathrm{mm}$, and exposure time was $20 \mathrm{~s}$ per degree for all sets. The scan width was $1.0^{\circ}$. Data collection was $85.3 \%$ complete to $29.98^{\circ}$ and $98.1 \%$ complete to $25^{\circ}$ in $\vartheta$. A total of 40964 partial and complete reflections were collected covering the indices, $\mathrm{h}=-17$ to $17, \mathrm{k}=-15$ to 15 , $1=-17$ to 17.2956 reflections were symmetry independent and the $R_{\text {int }}=0.0489$ indicated that the data was of better than average quality (0.07). Indexing and unit cell refinement indicated an othorhombic P lattice. The space group was found to be $\mathrm{P}$ mna (No. 53) with cell parameters $a=$ 13.1270 (2) $\AA, b=12.6480$ (2) $\AA, c=13.7450$ (3) $\AA, \alpha=90$ deg., $\beta=90$ deg., and $\gamma=90$ deg. The cell volume was 2282.09 (7) $\AA^{3}$, and the calculated density was $1.991 \mathrm{~g} / \mathrm{cm}^{3}$, with $Z=8$. The data were integrated and scaled using hkl-SCALEPACK. Solution by direct methods produced a complete heavy atom phasing model closely related to the proposed structure. All hydrogen atoms were located using a riding model. All non-hydrogen atoms were refined anisotropically by full-matrix least-square. The structure also contains a disordered counter ion, $\mathrm{PF}_{6}{ }^{-}$. An additional point of interest, the Iridium complex and counter ion sit on a mirror plane, hence the asymmetric unit consists of half of each moiety, the other half being generated by mirror operations. 


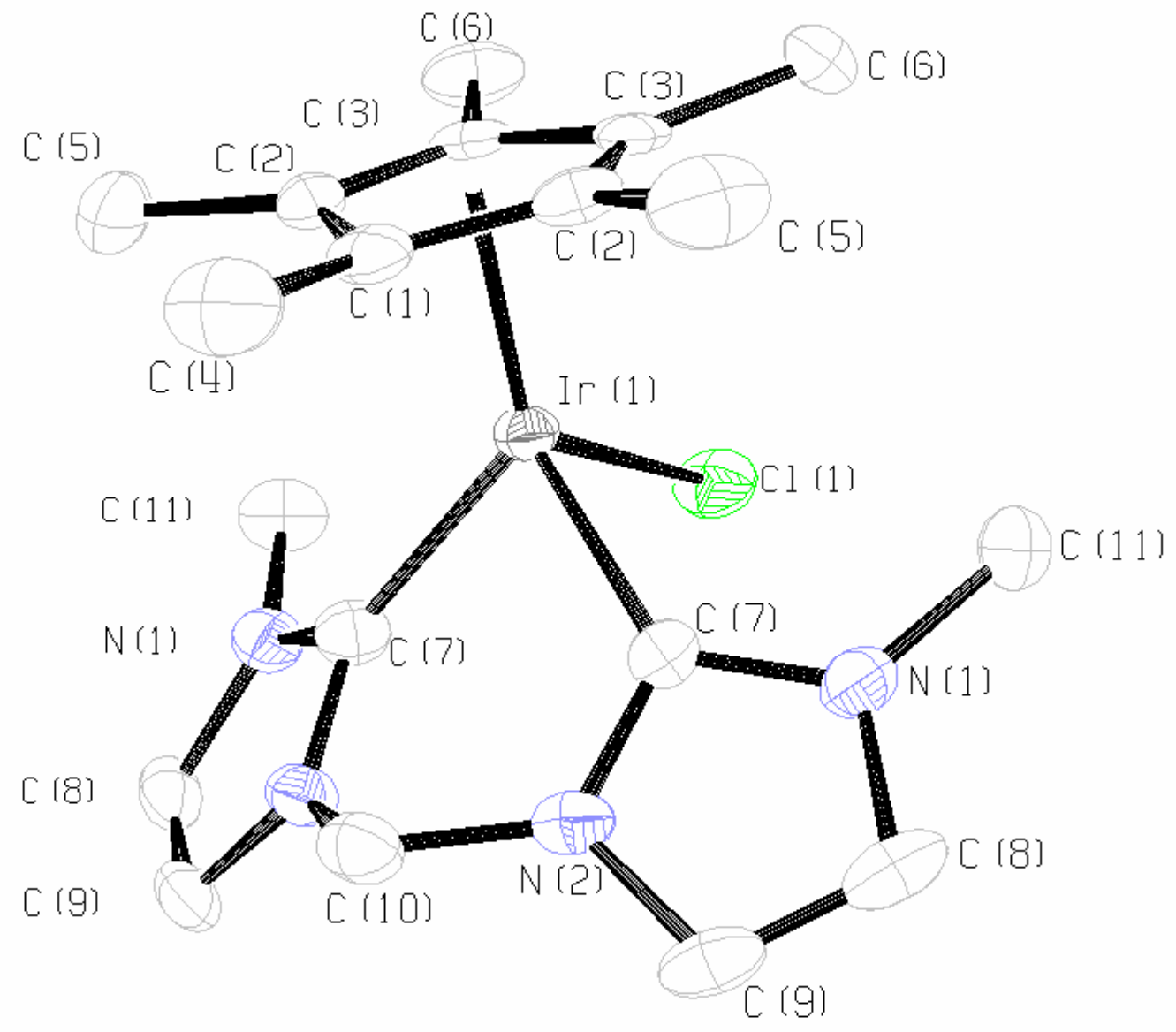




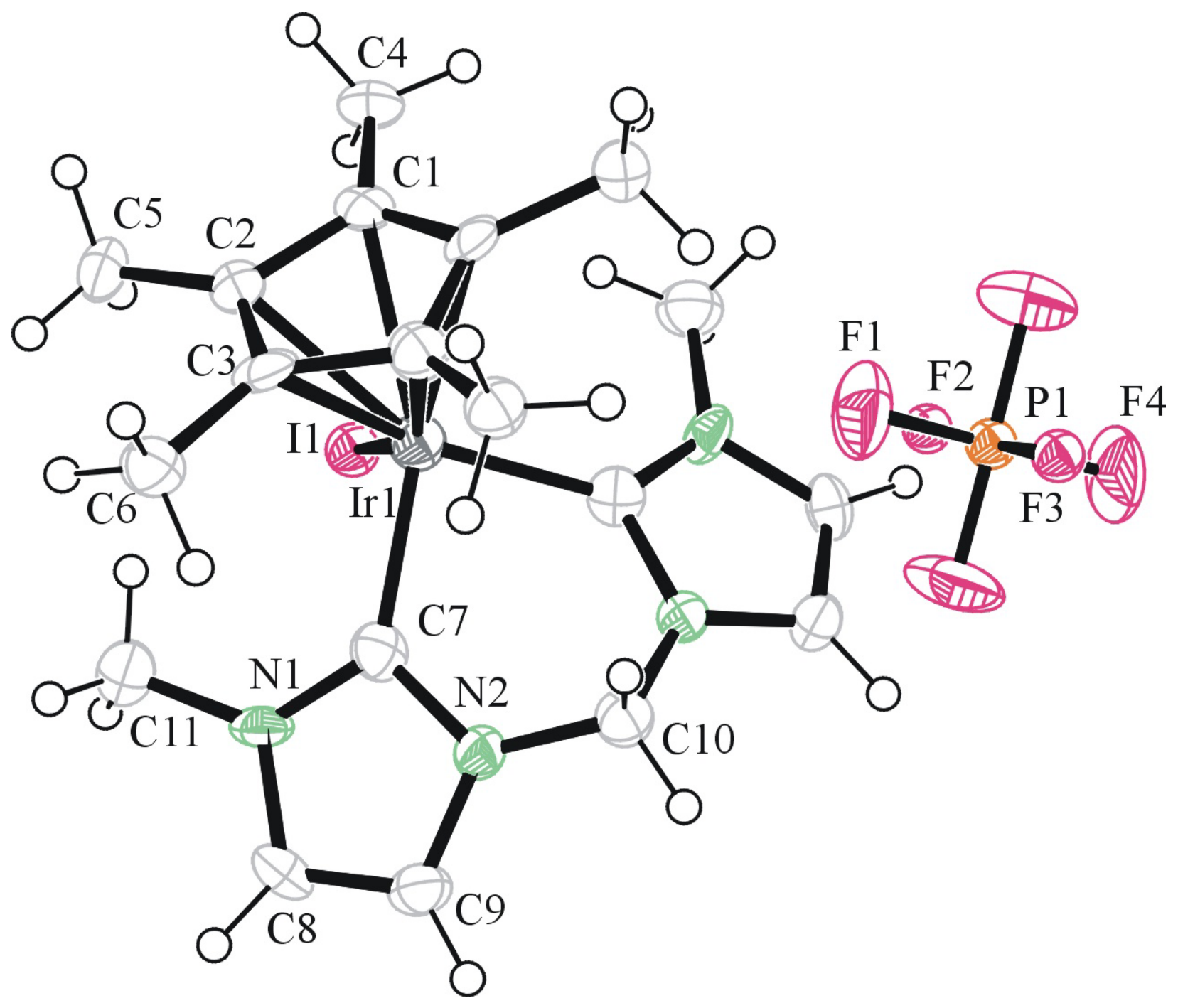

Table 1. Crystal data and structure refinement for $\left[\mathrm{CP}^{*} \operatorname{Ir}(\mathrm{C}-\mathrm{C}) \mathrm{I}\right]\left[\mathrm{PF}_{6}\right]$.

Empirical formula

Formula weight

Temperature

Wavelength

Crystal description/color

Crystal system, space group Unit cell dimensions
C19 H27 F6 I Ir N4 P

775.54

$130(2) \quad K$

$0.71073 \mathrm{~A}$

prism / yellow

'Orthorhombic', 'P

$\mathrm{a}=13.9510(8) \mathrm{A}$ alpha $=90 \mathrm{deg}$.

$\mathrm{b}=12.2730(8) \mathrm{A}$ beta $=90$ deg.

$\mathrm{C}=13.8420(10) \mathrm{A}$ gamma $=90 \mathrm{deg}$. 


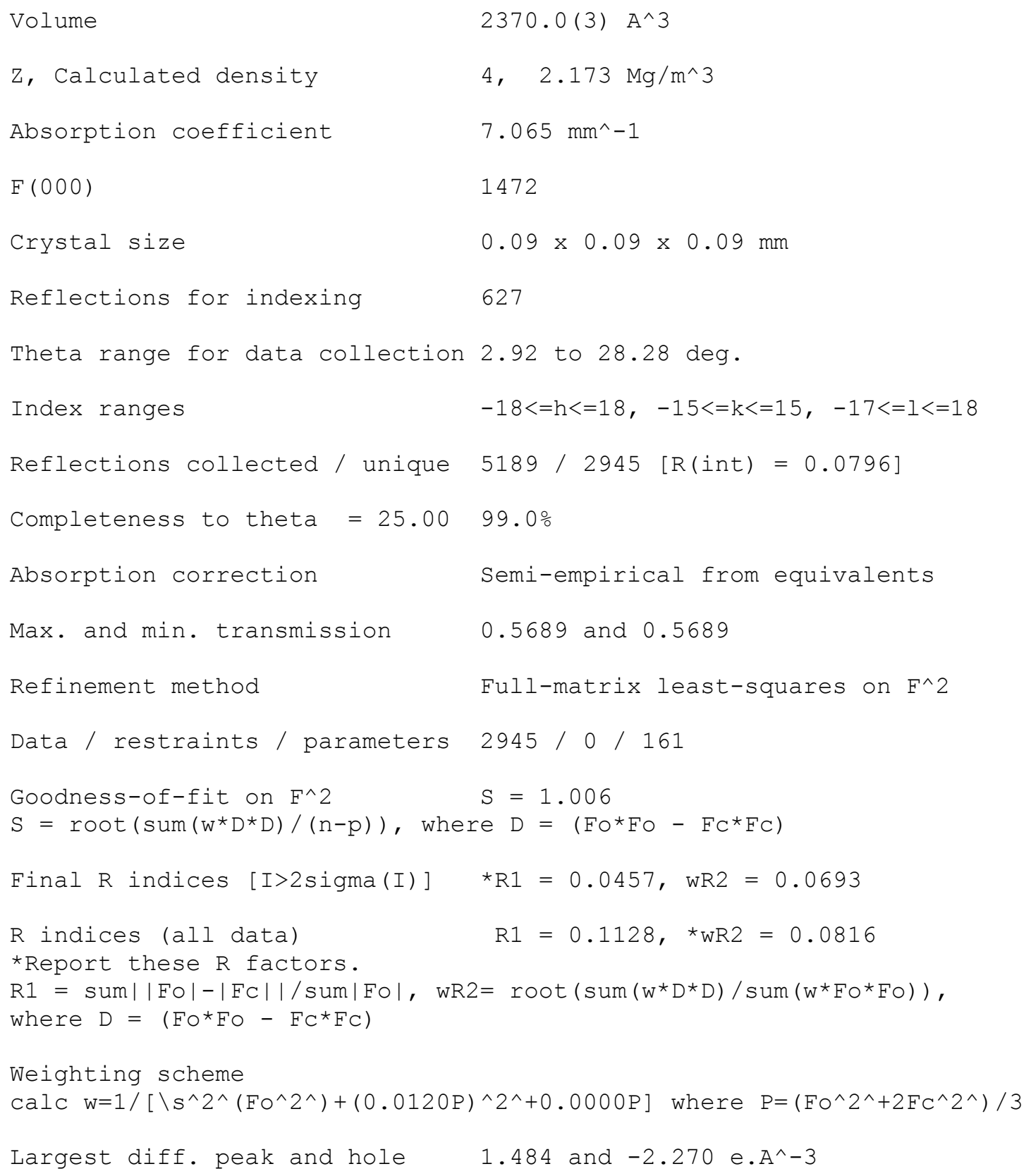


Table 2. Atomic coordinates $\left(x 1^{\wedge} 4\right)$ and equivalent isotropic displacement parameters $\left(A^{\wedge} 2 \times 10^{\wedge} 3\right)$ for Ir-I.

$\mathrm{U}(\mathrm{eq})$ is defined as one third of the trace of the orthogonalized Uij tensor.

\begin{tabular}{|c|c|c|c|c|}
\hline & $x$ & y & z & $\mathrm{U}(\mathrm{eq})$ \\
\hline $\operatorname{Ir}(1)$ & $3847(1)$ & 2500 & $1673(1)$ & $24(1)$ \\
\hline$I(1)$ & $2616(1)$ & 2500 & $3174(1)$ & $37(1)$ \\
\hline$P(1)$ & $308(2)$ & 7500 & $1768(2)$ & $30(1)$ \\
\hline $\mathrm{F}(1)$ & $996(4)$ & $6589(5)$ & $2187(4)$ & $82(2)$ \\
\hline$F(2)$ & $914(6)$ & 7500 & $802(5)$ & $82(3)$ \\
\hline$F(3)$ & $-262(6)$ & 7500 & $2745(5)$ & $85(3)$ \\
\hline$F(4)$ & $-364(4)$ & $8407(5)$ & $1363(4)$ & $90(2)$ \\
\hline $\mathrm{N}(1)$ & $2803(4)$ & $355(5)$ & $1215(4)$ & $31(2)$ \\
\hline $\mathrm{N}(2)$ & $2632(4)$ & $1537(5)$ & $85(4)$ & $27(2)$ \\
\hline$C(1)$ & $5237(7)$ & 2500 & $998(7)$ & $28(3)$ \\
\hline C (2) & $5219(5)$ & $1563(6)$ & $1632(5)$ & $30(2)$ \\
\hline C (3) & $5092(5)$ & $1912(5)$ & $2603(5)$ & $27(2)$ \\
\hline C (4) & $5488(7)$ & 2500 & $-50(7)$ & $33(3)$ \\
\hline C (5) & $5359(6)$ & $403(6)$ & $1288(5)$ & $34(2)$ \\
\hline$C(6)$ & $5076(5)$ & $1241(6)$ & $3488(4)$ & $32(2)$ \\
\hline C (7) & $3055(5)$ & $1374(7)$ & $970(5)$ & $30(2)$ \\
\hline $\mathrm{C}(8)$ & $2255(5)$ & $-136(6)$ & $495(5)$ & $31(2)$ \\
\hline C (9) & $2141(5)$ & $606(6)$ & $-209(5)$ & $33(2)$ \\
\hline$C(10)$ & $2785(8)$ & 2500 & $-494(7)$ & $36(3)$ \\
\hline$C(11)$ & $3056(5)$ & $-237(7)$ & $2098(6)$ & $41(2)$ \\
\hline
\end{tabular}


Table 3. Bond lengths [A] and angles [deg] for Ir-I.

\begin{tabular}{|c|c|}
\hline $\operatorname{Ir}(1)-C(7) \# 1$ & $2.019(8)$ \\
\hline $\operatorname{Ir}(1)-C(7)$ & $2.019(8)$ \\
\hline $\operatorname{Ir}(1)-C(1)$ & $2.153(10)$ \\
\hline $\operatorname{Ir}(1)-C(2) \# 1$ & $2.234(7)$ \\
\hline $\operatorname{Ir}(1)-C(2)$ & $2.234(7)$ \\
\hline $\operatorname{Ir}(1)-C(3)$ & $2.280(7)$ \\
\hline $\operatorname{Ir}(1)-C(3) \# 1$ & $2.280(7)$ \\
\hline $\operatorname{Ir}(1)-I(1)$ & $2.6962(8)$ \\
\hline$P(1)-F(4)$ & $1.559(5)$ \\
\hline$P(1)-F(4) \# 2$ & $1.559(5)$ \\
\hline$P(1)-F(3)$ & $1.569(7)$ \\
\hline$P(1)-F(2)$ & $1.581(7)$ \\
\hline$P(1)-F(1) \# 2$ & $1.584(5)$ \\
\hline$P(1)-F(1)$ & $1.584(5)$ \\
\hline$N(1)-C(7)$ & $1.342(9)$ \\
\hline$N(1)-C(8)$ & $1.393(9)$ \\
\hline$N(1)-C(11)$ & $1.466(9)$ \\
\hline$N(2)-C(7)$ & $1.375(8)$ \\
\hline$N(2)-C(9)$ & $1.394(9)$ \\
\hline$N(2)-C(10)$ & $1.443(8)$ \\
\hline$C(1)-C(2) \# 1$ & $1.447(9)$ \\
\hline$C(1)-C(2)$ & $1.447(9)$ \\
\hline$C(1)-C(4)$ & $1.493(13)$ \\
\hline$C(2)-C(3)$ & $1.421(9)$ \\
\hline$C(2)-C(5)$ & $1.514(10)$ \\
\hline$C(3)-C(3) \# 1$ & $1.443(13)$ \\
\hline$C(3)-C(6)$ & $1.477(8)$ \\
\hline $\mathrm{C}(4)-\mathrm{H}(4 \mathrm{~A})$ & 0.9800 \\
\hline$C(4)-H(4 B)$ & 0.9800 \\
\hline $\mathrm{C}(4)-\mathrm{H}(4 \mathrm{C})$ & 0.9800 \\
\hline $\mathrm{C}(5)-\mathrm{H}(5 \mathrm{~A})$ & 0.9800 \\
\hline $\mathrm{C}(5)-\mathrm{H}(5 \mathrm{~B})$ & 0.9800 \\
\hline $\mathrm{C}(5)-\mathrm{H}(5 \mathrm{C})$ & 0.9800 \\
\hline$C(6)-H(6 A)$ & 0.9800 \\
\hline$C(6)-H(6 B)$ & 0.9800 \\
\hline $\mathrm{C}(6)-\mathrm{H}(6 \mathrm{C})$ & 0.9800 \\
\hline$C(8)-C(9)$ & $1.343(10)$ \\
\hline $\mathrm{C}(8)-\mathrm{H}(8)$ & 0.9500 \\
\hline $\mathrm{C}(9)-\mathrm{H}(9)$ & 0.9500 \\
\hline $\mathrm{C}(10)-\mathrm{N}(2) \# 1$ & $1.443(8)$ \\
\hline $\mathrm{C}(10)-\mathrm{H}(10 \mathrm{~A})$ & 0.9900 \\
\hline $\mathrm{C}(10)-\mathrm{H}(10 \mathrm{~B})$ & 0.9900 \\
\hline $\mathrm{C}(11)-\mathrm{H}(11 \mathrm{~A})$ & 0.9800 \\
\hline $\mathrm{C}(11)-\mathrm{H}(11 \mathrm{~B})$ & 0.9800 \\
\hline $\mathrm{C}(11)-\mathrm{H}(11 \mathrm{C})$ & 0.9800 \\
\hline$C(7) \# 1-\operatorname{Ir}(1)-C(7)$ & $86.4(4)$ \\
\hline$C(7) \# 1-\operatorname{Ir}(1)-C(1)$ & $106.5(3)$ \\
\hline$C(7)-\operatorname{Ir}(1)-C(1)$ & $106.5(3)$ \\
\hline$C(7) \# 1-\operatorname{Ir}(1)-C(2) \# 1$ & $96.0(3)$ \\
\hline$C(7)-\operatorname{Ir}(1)-C(2) \# 1$ & $144.0(3)$ \\
\hline$C(1)-\operatorname{Ir}(1)-C(2) \# 1$ & $38.5(2)$ \\
\hline$C(7) \# 1-\operatorname{Ir}(1)-C(2)$ & $144.0(3)$ \\
\hline
\end{tabular}




\begin{tabular}{|c|c|}
\hline$C(7)-\operatorname{Ir}(1)-C(2)$ & $96.0(3)$ \\
\hline$C(1)-\operatorname{Ir}(1)-C(2)$ & $38.5(2)$ \\
\hline$C(2) \# 1-\operatorname{Ir}(1)-C(2)$ & $62.0(4)$ \\
\hline$C(7) \# 1-\operatorname{Ir}(1)-C(3)$ & $154.9(3)$ \\
\hline$C(7)-\operatorname{Ir}(1)-C(3)$ & $118.2(3)$ \\
\hline$C(1)-\operatorname{Ir}(1)-C(3)$ & $63.8(3)$ \\
\hline$C(2) \# 1-\operatorname{Ir}(1)-C(3)$ & $61.6(2)$ \\
\hline$C(2)-\operatorname{Ir}(1)-C(3)$ & $36.7(2)$ \\
\hline$C(7) \# 1-\operatorname{Ir}(1)-C(3) \# 1$ & $118.2(3)$ \\
\hline$C(7)-\operatorname{Ir}(1)-C(3) \# 1$ & $154.9(3)$ \\
\hline$C(1)-\operatorname{Ir}(1)-C(3) \# 1$ & $63.8(3)$ \\
\hline$C(2) \# 1-\operatorname{Ir}(1)-C(3) \# 1$ & $36.7(2)$ \\
\hline$C(2)-\operatorname{Ir}(1)-C(3) \# 1$ & $61.6(2)$ \\
\hline$C(3)-\operatorname{Ir}(1)-C(3) \# 1$ & $36.9(3)$ \\
\hline$C(7) \# 1-\operatorname{Ir}(1)-I(1)$ & $91.3(2)$ \\
\hline$C(7)-\operatorname{Ir}(1)-I(1)$ & $91.3(2)$ \\
\hline$C(1)-\operatorname{Ir}(1)-I(1)$ & $155.3(2)$ \\
\hline$C(2) \# 1-\operatorname{Ir}(1)-I(1)$ & $124.42(19)$ \\
\hline$C(2)-\operatorname{Ir}(1)-I(1)$ & $124.42(19)$ \\
\hline$C(3)-\operatorname{Ir}(1)-I(1)$ & $92.88(18)$ \\
\hline$C(3) \# 1-\operatorname{Ir}(1)-I(1)$ & $92.88(18)$ \\
\hline$F(4)-P(1)-F(4) \# 2$ & $91.1(5)$ \\
\hline$F(4)-P(1)-F(3)$ & $90.3(4)$ \\
\hline$F(4) \# 2-P(1)-F(3)$ & $90.3(4)$ \\
\hline$F(4)-P(1)-F(2)$ & $91.0(3)$ \\
\hline$F(4) \# 2-P(1)-F(2)$ & $91.0(3)$ \\
\hline$F(3)-P(1)-F(2)$ & $178.1(5)$ \\
\hline $\mathrm{F}(4)-\mathrm{P}(1)-\mathrm{F}(1) \# 2$ & $89.5(3)$ \\
\hline $\mathrm{F}(4) \# 2-\mathrm{P}(1)-\mathrm{F}(1) \# 2$ & $179.3(4)$ \\
\hline$F(3)-P(1)-F(1) \# 2$ & $89.5(3)$ \\
\hline$F(2)-P(1)-F(1) \# 2$ & $89.2(3)$ \\
\hline$F(4)-P(1)-F(1)$ & $179.3(4)$ \\
\hline$F(4) \# 2-P(1)-F(1)$ & $89.5(3)$ \\
\hline$F(3)-P(1)-F(1)$ & $89.5(3)$ \\
\hline$F(2)-P(1)-F(1)$ & $89.2(3)$ \\
\hline$F(1) \# 2-P(1)-F(1)$ & $89.8(5)$ \\
\hline$C(7)-N(1)-C(8)$ & $111.5(6)$ \\
\hline$C(7)-N(1)-C(11)$ & $127.5(6)$ \\
\hline$C(8)-N(1)-C(11)$ & $121.0(6)$ \\
\hline$C(7)-N(2)-C(9)$ & $110.6(6)$ \\
\hline$C(7)-N(2)-C(10)$ & $123.4(7)$ \\
\hline$C(9)-N(2)-C(10)$ & $125.6(6)$ \\
\hline$C(2) \# 1-C(1)-C(2)$ & $105.3(8)$ \\
\hline$C(2) \# 1-C(1)-C(4)$ & $126.4(4)$ \\
\hline$C(2)-C(1)-C(4)$ & $126.4(4)$ \\
\hline$C(2) \# 1-C(1)-\operatorname{Ir}(1)$ & $73.8(5)$ \\
\hline$C(2)-C(1)-\operatorname{Ir}(1)$ & $73.8(5)$ \\
\hline$C(4)-C(1)-\operatorname{Ir}(1)$ & $129.3(7)$ \\
\hline$C(3)-C(2)-C(1)$ & $109.6(7)$ \\
\hline$C(3)-C(2)-C(5)$ & $126.7(6)$ \\
\hline$C(1)-C(2)-C(5)$ & $123.7(7)$ \\
\hline$C(3)-C(2)-\operatorname{Ir}(1)$ & $73.4(4)$ \\
\hline$C(1)-C(2)-\operatorname{Ir}(1)$ & $67.7(5)$ \\
\hline$C(5)-C(2)-\operatorname{Ir}(1)$ & $127.0(5)$ \\
\hline$C(2)-C(3)-C(3) \# 1$ & $107.6(4)$ \\
\hline$C(2)-C(3)-C(6)$ & $128.2(6)$ \\
\hline$C(3) \# 1-C(3)-C(6)$ & $123.9(4)$ \\
\hline
\end{tabular}




\begin{tabular}{|c|c|}
\hline$C(2)-C(3)-\operatorname{Ir}(1)$ & $69.9(4)$ \\
\hline$C(3) \# 1-C(3)-\operatorname{Ir}(1)$ & $71.56(17)$ \\
\hline$C(6)-C(3)-\operatorname{Ir}(1)$ & $129.3(5)$ \\
\hline $\mathrm{C}(1)-\mathrm{C}(4)-\mathrm{H}(4 \mathrm{~A})$ & 109.5 \\
\hline $\mathrm{C}(1)-\mathrm{C}(4)-\mathrm{H}(4 \mathrm{~B})$ & 109.5 \\
\hline $\mathrm{H}(4 \mathrm{~A})-\mathrm{C}(4)-\mathrm{H}(4 \mathrm{~B})$ & 109.5 \\
\hline $\mathrm{C}(1)-\mathrm{C}(4)-\mathrm{H}(4 \mathrm{C})$ & 109.5 \\
\hline $\mathrm{H}(4 \mathrm{~A})-\mathrm{C}(4)-\mathrm{H}(4 \mathrm{C})$ & 109.5 \\
\hline $\mathrm{H}(4 \mathrm{~B})-\mathrm{C}(4)-\mathrm{H}(4 \mathrm{C})$ & 109.5 \\
\hline $\mathrm{C}(2)-\mathrm{C}(5)-\mathrm{H}(5 \mathrm{~A})$ & 109.5 \\
\hline $\mathrm{C}(2)-\mathrm{C}(5)-\mathrm{H}(5 \mathrm{~B})$ & 109.5 \\
\hline $\mathrm{H}(5 \mathrm{~A})-\mathrm{C}(5)-\mathrm{H}(5 \mathrm{~B})$ & 109.5 \\
\hline$C(2)-C(5)-H(5 C)$ & 109.5 \\
\hline $\mathrm{H}(5 \mathrm{~A})-\mathrm{C}(5)-\mathrm{H}(5 \mathrm{C})$ & 109.5 \\
\hline $\mathrm{H}(5 \mathrm{~B})-\mathrm{C}(5)-\mathrm{H}(5 \mathrm{C})$ & 109.5 \\
\hline$C(3)-C(6)-H(6 A)$ & 109.5 \\
\hline $\mathrm{C}(3)-\mathrm{C}(6)-\mathrm{H}(6 \mathrm{~B})$ & 109.5 \\
\hline $\mathrm{H}(6 \mathrm{~A})-\mathrm{C}(6)-\mathrm{H}(6 \mathrm{~B})$ & 109.5 \\
\hline$C(3)-C(6)-H(6 C)$ & 109.5 \\
\hline $\mathrm{H}(6 \mathrm{~A})-\mathrm{C}(6)-\mathrm{H}(6 \mathrm{C})$ & 109.5 \\
\hline $\mathrm{H}(6 \mathrm{~B})-\mathrm{C}(6)-\mathrm{H}(6 \mathrm{C})$ & 109.5 \\
\hline $\mathrm{N}(1)-\mathrm{C}(7)-\mathrm{N}(2)$ & $104.4(6)$ \\
\hline$N(1)-C(7)-\operatorname{Ir}(1)$ & $131.3(5)$ \\
\hline $\mathrm{N}(2)-\mathrm{C}(7)-\operatorname{Ir}(1)$ & $124.4(5)$ \\
\hline $\mathrm{C}(9)-\mathrm{C}(8)-\mathrm{N}(1)$ & $106.9(7)$ \\
\hline $\mathrm{C}(9)-\mathrm{C}(8)-\mathrm{H}(8)$ & 126.5 \\
\hline $\mathrm{N}(1)-\mathrm{C}(8)-\mathrm{H}(8)$ & 126.5 \\
\hline$C(8)-C(9)-N(2)$ & $106.6(6)$ \\
\hline $\mathrm{C}(8)-\mathrm{C}(9)-\mathrm{H}(9)$ & 126.7 \\
\hline $\mathrm{N}(2)-\mathrm{C}(9)-\mathrm{H}(9)$ & 126.7 \\
\hline$N(2)-C(10)-N(2) \# 1$ & $109.9(8)$ \\
\hline $\mathrm{N}(2)-\mathrm{C}(10)-\mathrm{H}(10 \mathrm{~A})$ & 109.7 \\
\hline $\mathrm{N}(2) \# 1-\mathrm{C}(10)-\mathrm{H}(10 \mathrm{~A})$ & 109.7 \\
\hline $\mathrm{N}(2)-\mathrm{C}(10)-\mathrm{H}(10 \mathrm{~B})$ & 109.7 \\
\hline $\mathrm{N}(2) \# 1-\mathrm{C}(10)-\mathrm{H}(10 \mathrm{~B})$ & 109.7 \\
\hline $\mathrm{H}(10 \mathrm{~A})-\mathrm{C}(10)-\mathrm{H}(10 \mathrm{~B})$ & 108.2 \\
\hline $\mathrm{N}(1)-\mathrm{C}(11)-\mathrm{H}(11 \mathrm{~A})$ & 109.5 \\
\hline $\mathrm{N}(1)-\mathrm{C}(11)-\mathrm{H}(11 \mathrm{~B})$ & 109.5 \\
\hline $\mathrm{H}(11 \mathrm{~A})-\mathrm{C}(11)-\mathrm{H}(11 \mathrm{~B})$ & 109.5 \\
\hline $\mathrm{N}(1)-\mathrm{C}(11)-\mathrm{H}(11 \mathrm{C})$ & 109.5 \\
\hline $\mathrm{H}(11 \mathrm{~A})-\mathrm{C}(11)-\mathrm{H}(11 \mathrm{C})$ & 109.5 \\
\hline $\mathrm{H}(11 \mathrm{~B})-\mathrm{C}(11)-\mathrm{H}(11 \mathrm{C})$ & 109.5 \\
\hline
\end{tabular}

Symmetry transformations used to generate equivalent atoms: $\# 1 x,-y+1 / 2, z \quad \# 2 x,-y+3 / 2, z$ 
Table 4. Anisotropic displacement parameters ( $\left.A^{\wedge} 2 \times 10^{\wedge} 3\right)$ for Ir-I. The anisotropic displacement factor exponent takes the form:

$-2 \mathrm{pi}^{\wedge} 2\left[\mathrm{~h}^{\wedge} 2 \mathrm{a}^{\star \wedge} 2 \mathrm{U} 11+\ldots+2 \mathrm{~h} \mathrm{k} \mathrm{a}^{\star} \mathrm{b} \mathrm{b}^{\star} \mathrm{U} 12\right]$

\begin{tabular}{|c|c|c|c|c|c|c|}
\hline & U11 & U22 & U33 & U23 & U13 & U12 \\
\hline $\operatorname{Ir}(1)$ & $24(1)$ & $25(1)$ & $23(1)$ & 0 & $-1(1)$ & 0 \\
\hline I (1) & 27 (1) & $51(1)$ & $34(1)$ & 0 & $5(1)$ & 0 \\
\hline P (1) & $37(2)$ & $23(2)$ & $30(2)$ & 0 & $1(1)$ & 0 \\
\hline $\mathrm{F}(1)$ & $78(5)$ & $71(4)$ & $97(4)$ & $34(3)$ & $-6(3)$ & $26(3)$ \\
\hline $\mathrm{F}(2)$ & $127(8)$ & $50(5)$ & 70 ( 5) & 0 & $42(5)$ & 0 \\
\hline $\mathrm{F}(3)$ & $101(7)$ & $92(7)$ & $60(5)$ & 0 & $48(5)$ & 0 \\
\hline $\mathrm{F}(4)$ & $89(4)$ & $59(4)$ & $123(5)$ & $36(3)$ & $-19(4)$ & $27(3)$ \\
\hline N (1) & $27(4)$ & $33(4)$ & 32 (3) & $-4(3)$ & $-8(3)$ & $-11(3)$ \\
\hline $\mathrm{N}(2)$ & $34(4)$ & $25(4)$ & $23(3)$ & $0(3)$ & $-4(3)$ & $2(3)$ \\
\hline C (1) & $23(6)$ & $33(7)$ & $29(6)$ & 0 & $-9(5)$ & 0 \\
\hline C (2) & $19(4)$ & $38(5)$ & $33(4)$ & $-7(4)$ & $-12(4)$ & $0(3)$ \\
\hline C (3) & $11(4)$ & $29(4)$ & $40(4)$ & $3(3)$ & $-1(3)$ & $2(3)$ \\
\hline C (4) & $34(7)$ & $36(7)$ & $30(6)$ & 0 & $1(5)$ & 0 \\
\hline C (5) & $34(5)$ & $30(5)$ & $40(4)$ & $-4(4)$ & $-4(4)$ & $1(4)$ \\
\hline$C(6)$ & $32(4)$ & 35 ( 5$)$ & 31 (4) & $10(3)$ & $-3(3)$ & $5(4)$ \\
\hline C (7) & $33(5)$ & 31 (5) & 27 ( 4) & $3(4)$ & $4(3)$ & $-4(4)$ \\
\hline C ( 8$)$ & $37(5)$ & $20(5)$ & 37 ( 4) & $-4(4)$ & $5(4)$ & $-8(4)$ \\
\hline C (9) & $34(5)$ & $34(5)$ & $29(4)$ & $-6(4)$ & $-6(3)$ & $-1(4)$ \\
\hline$C(10)$ & $29(7)$ & 35 ( 8 ) & $43(7)$ & 0 & $-15(5)$ & 0 \\
\hline C (11) & $42(6)$ & $39(6)$ & $44(5)$ & $7(4)$ & $-7(4)$ & $1(4)$ \\
\hline
\end{tabular}


Table 5. Hydrogen coordinates $\left(x 1^{\wedge} 4\right)$ and isotropic displacement parameters $\left(A^{\wedge} 2 \times 10^{\wedge} 3\right)$ for Ir-I.

\begin{tabular}{lrrrl}
\hline & & & & \\
& $x$ & $y$ & $z$ & $U(e q)$ \\
\hline$H(4 A)$ & 5290 & 3192 & -341 & 50 \\
H (4B) & 5158 & 1897 & -373 & 50 \\
H (4C) & 6183 & 2411 & -124 & 50 \\
H (5A) & 5221 & -102 & 1819 & 52 \\
H (5B) & 6023 & 304 & 1074 & 52 \\
H (5C) & 4923 & 256 & 748 & 52 \\
H (6A) & 5638 & 1410 & 3884 & 49 \\
H (6B) & 5086 & 468 & 3312 & 49 \\
H (6C) & 4492 & 1399 & 3856 & 49 \\
H (8) & 2008 & -857 & 502 & 38 \\
H (9) & 1793 & 513 & -794 & 39 \\
H (10A) & 2336 & 2500 & -1048 & 43 \\
H (10B) & 3447 & 2500 & -750 & 43 \\
H (11A) & 3421 & -892 & 1930 & 62 \\
H (11B) & 2470 & -447 & 2441 & 62 \\
H (11C) & 3446 & 233 & 2515 & 62 \\
& & & & \\
\hline
\end{tabular}


Table 6. Torsion angles [deg] for Ir-I.

\begin{tabular}{|c|c|}
\hline$C(7) \# 1-\operatorname{Ir}(1)-C(1)-C(2) \# 1$ & $78.6(5)$ \\
\hline$C(7)-\operatorname{Ir}(1)-C(1)-C(2) \# 1$ & $169.7(4)$ \\
\hline$C(2)-\operatorname{Ir}(1)-C(1)-C(2) \# 1$ & $-111.7(8)$ \\
\hline$C(3)-\operatorname{Ir}(1)-C(1)-C(2) \# 1$ & $-76.5(5)$ \\
\hline C (3) \#1-Ir (1) -C (1) -C (2) \#1 & $-35.2(4)$ \\
\hline$I(1)-\operatorname{Ir}(1)-C(1)-C(2) \# 1$ & $-55.9(4)$ \\
\hline$C(7) \# 1-\operatorname{Ir}(1)-C(1)-C(2)$ & $-169.7(4)$ \\
\hline$C(7)-\operatorname{Ir}(1)-C(1)-C(2)$ & $-78.6(5)$ \\
\hline$C(2) \# 1-\operatorname{Ir}(1)-C(1)-C(2)$ & $111.7(8)$ \\
\hline$C(3)-\operatorname{Ir}(1)-C(1)-C(2)$ & $35.2(4)$ \\
\hline$C(3) \# 1-\operatorname{Ir}(1)-C(1)-C(2)$ & $76.5(5)$ \\
\hline$I(1)-\operatorname{Ir}(1)-C(1)-C(2)$ & $55.9(4)$ \\
\hline$C(7) \# 1-\operatorname{Ir}(1)-C(1)-C(4)$ & $-45.6(2)$ \\
\hline$C(7)-\operatorname{Ir}(1)-C(1)-C(4)$ & $45.6(2)$ \\
\hline$C(2) \# 1-\operatorname{Ir}(1)-C(1)-C(4)$ & $-124.1(4)$ \\
\hline$C(2)-\operatorname{Ir}(1)-C(1)-C(4)$ & $124.1(4)$ \\
\hline$C(3)-\operatorname{Ir}(1)-C(1)-C(4)$ & $159.35(19)$ \\
\hline$C(3) \# 1-\operatorname{Ir}(1)-C(1)-C(4)$ & $-159.35(19)$ \\
\hline$I(1)-\operatorname{Ir}(1)-C(1)-C(4)$ & 180.0 \\
\hline$C(2) \# 1-C(1)-C(2)-C(3)$ & $5.9(10)$ \\
\hline$C(4)-C(1)-C(2)-C(3)$ & $171.0(8)$ \\
\hline $\operatorname{Ir}(1)-C(1)-C(2)-C(3)$ & $-61.7(5)$ \\
\hline$C(2) \# 1-C(1)-C(2)-C(5)$ & $-171.7(5)$ \\
\hline$C(4)-C(1)-C(2)-C(5)$ & $-6.6(14)$ \\
\hline $\operatorname{Ir}(1)-C(1)-C(2)-C(5)$ & $120.6(7)$ \\
\hline$C(2) \# 1-C(1)-C(2)-\operatorname{Ir}(1)$ & $67.7(6)$ \\
\hline$C(4)-C(1)-C(2)-\operatorname{Ir}(1)$ & $-127.2(10)$ \\
\hline$C(7) \# 1-\operatorname{Ir}(1)-C(2)-C(3)$ & $137.0(5)$ \\
\hline$C(7)-\operatorname{Ir}(1)-C(2)-C(3)$ & $-130.9(4)$ \\
\hline$C(1)-\operatorname{Ir}(1)-C(2)-C(3)$ & $120.0(6)$ \\
\hline$C(2) \# 1-\operatorname{Ir}(1)-C(2)-C(3)$ & $79.1(4)$ \\
\hline$C(3) \# 1-\operatorname{Ir}(1)-C(2)-C(3)$ & $37.3(4)$ \\
\hline$I(1)-\operatorname{Ir}(1)-C(2)-C(3)$ & $-35.1(5)$ \\
\hline$C(7) \# 1-\operatorname{Ir}(1)-C(2)-C(1)$ & $17.0(7)$ \\
\hline$C(7)-\operatorname{Ir}(1)-C(2)-C(1)$ & $109.1(5)$ \\
\hline$C(2) \# 1-\operatorname{Ir}(1)-C(2)-C(1)$ & $-40.9(5)$ \\
\hline$C(3)-\operatorname{Ir}(1)-C(2)-C(1)$ & $-120.0(6)$ \\
\hline$C(3) \# 1-\operatorname{Ir}(1)-C(2)-C(1)$ & $-82.8(5)$ \\
\hline$I(1)-\operatorname{Ir}(1)-C(2)-C(1)$ & $-155.2(3)$ \\
\hline$C(7) \# 1-\operatorname{Ir}(1)-C(2)-C(5)$ & $-99.2(7)$ \\
\hline$C(7)-\operatorname{Ir}(1)-C(2)-C(5)$ & $-7.1(7)$ \\
\hline$C(1)-\operatorname{Ir}(1)-C(2)-C(5)$ & $-116.2(8)$ \\
\hline$C(2) \# 1-\operatorname{Ir}(1)-C(2)-C(5)$ & $-157.1(5)$ \\
\hline$C(3)-\operatorname{Ir}(1)-C(2)-C(5)$ & $123.8(8)$ \\
\hline$C(3) \# 1-\operatorname{Ir}(1)-C(2)-C(5)$ & $161.1(7)$ \\
\hline$I(1)-\operatorname{Ir}(1)-C(2)-C(5)$ & $88.6(6)$ \\
\hline$C(1)-C(2)-C(3)-C(3) \# 1$ & $-3.8(7)$ \\
\hline$C(5)-C(2)-C(3)-C(3) \# 1$ & $173.8(6)$ \\
\hline $\operatorname{Ir}(1)-C(2)-C(3)-C(3) \# 1$ & $-62.02(19)$ \\
\hline$C(1)-C(2)-C(3)-C(6)$ & $-177.0(8)$ \\
\hline$C(5)-C(2)-C(3)-C(6)$ & $0.6(12)$ \\
\hline $\operatorname{Ir}(1)-C(2)-C(3)-C(6)$ & $124.7(7)$ \\
\hline$C(1)-C(2)-C(3)-\operatorname{Ir}(1)$ & $58.3(6)$ \\
\hline
\end{tabular}




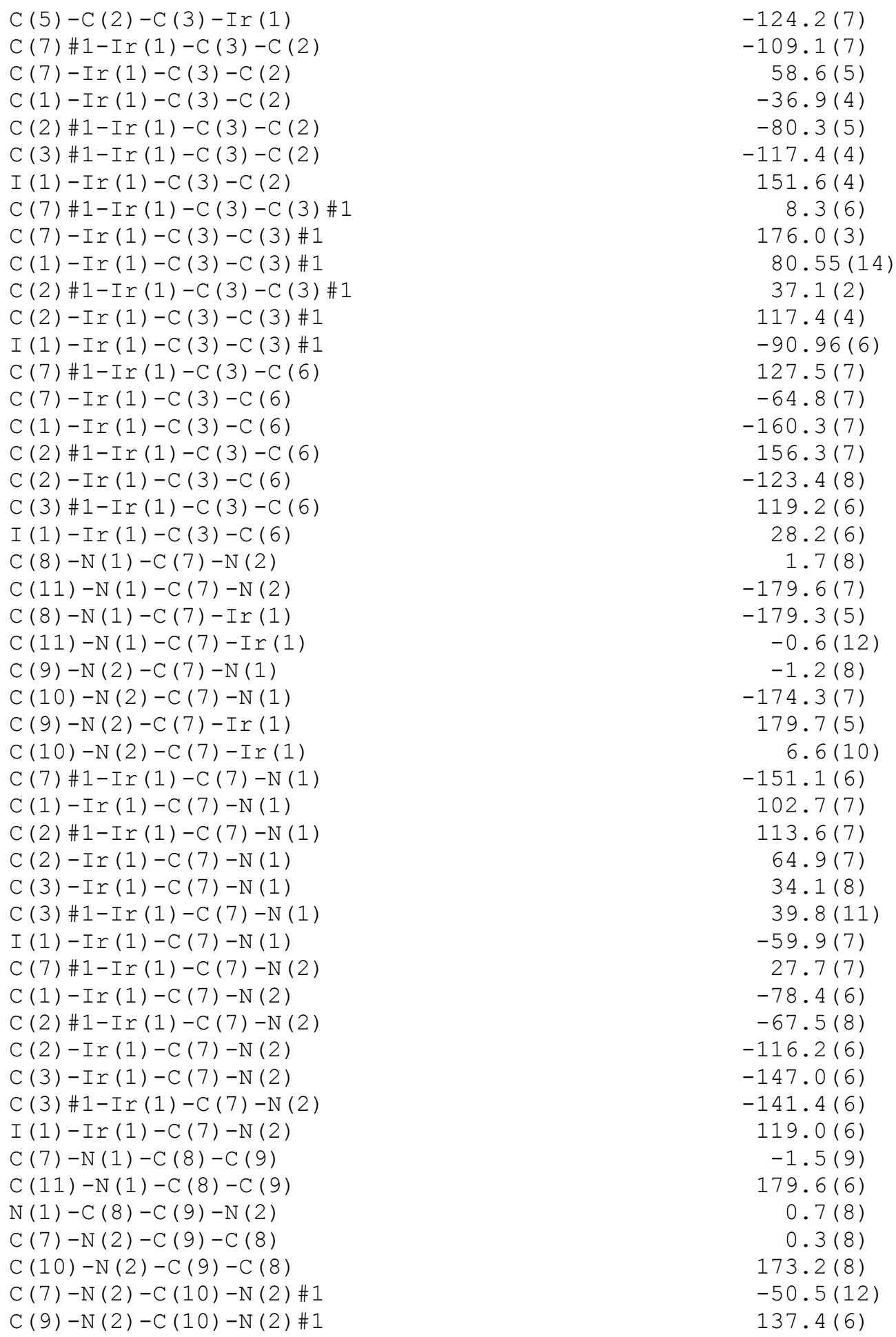

Symmetry transformations used to generate equivalent atoms: \#1 $x,-y+1 / 2, z \quad \# 2 x,-y+3 / 2, z$ 


\section{X-ray Structure of $\left[\mathrm{Cp}^{*} \operatorname{Ir}(\mathrm{C}-\mathrm{C}) \mathbf{I}\right]\left[\mathrm{PF}_{6}\right]$.}

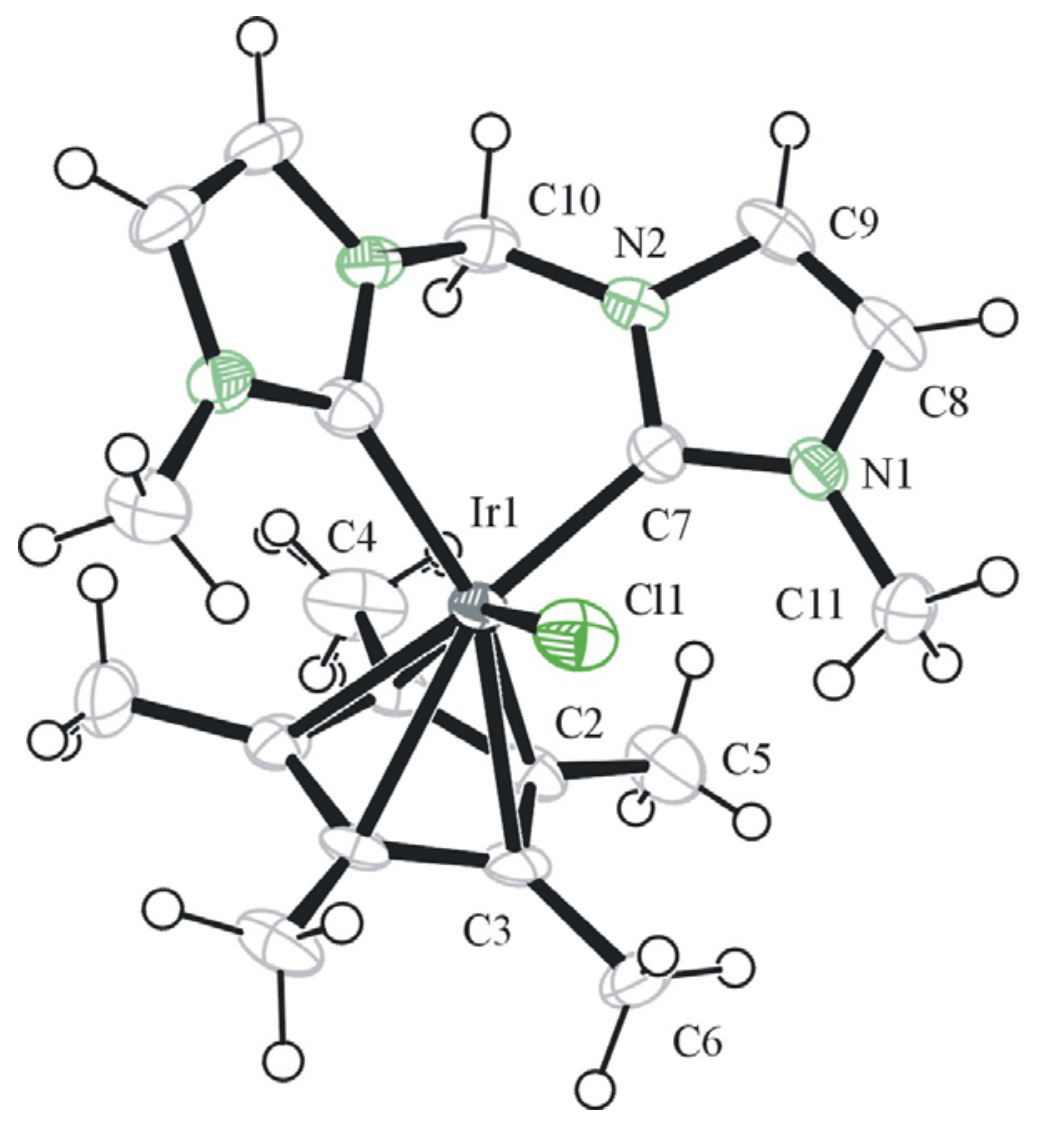

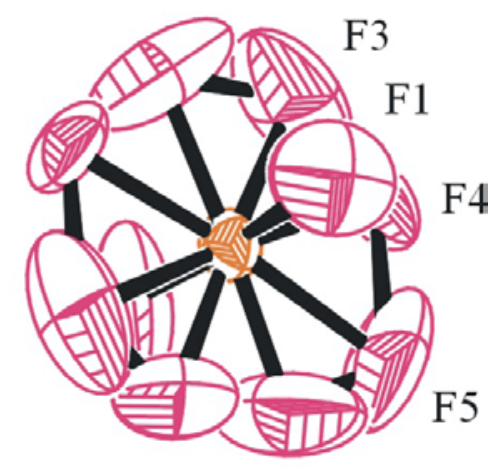

F6

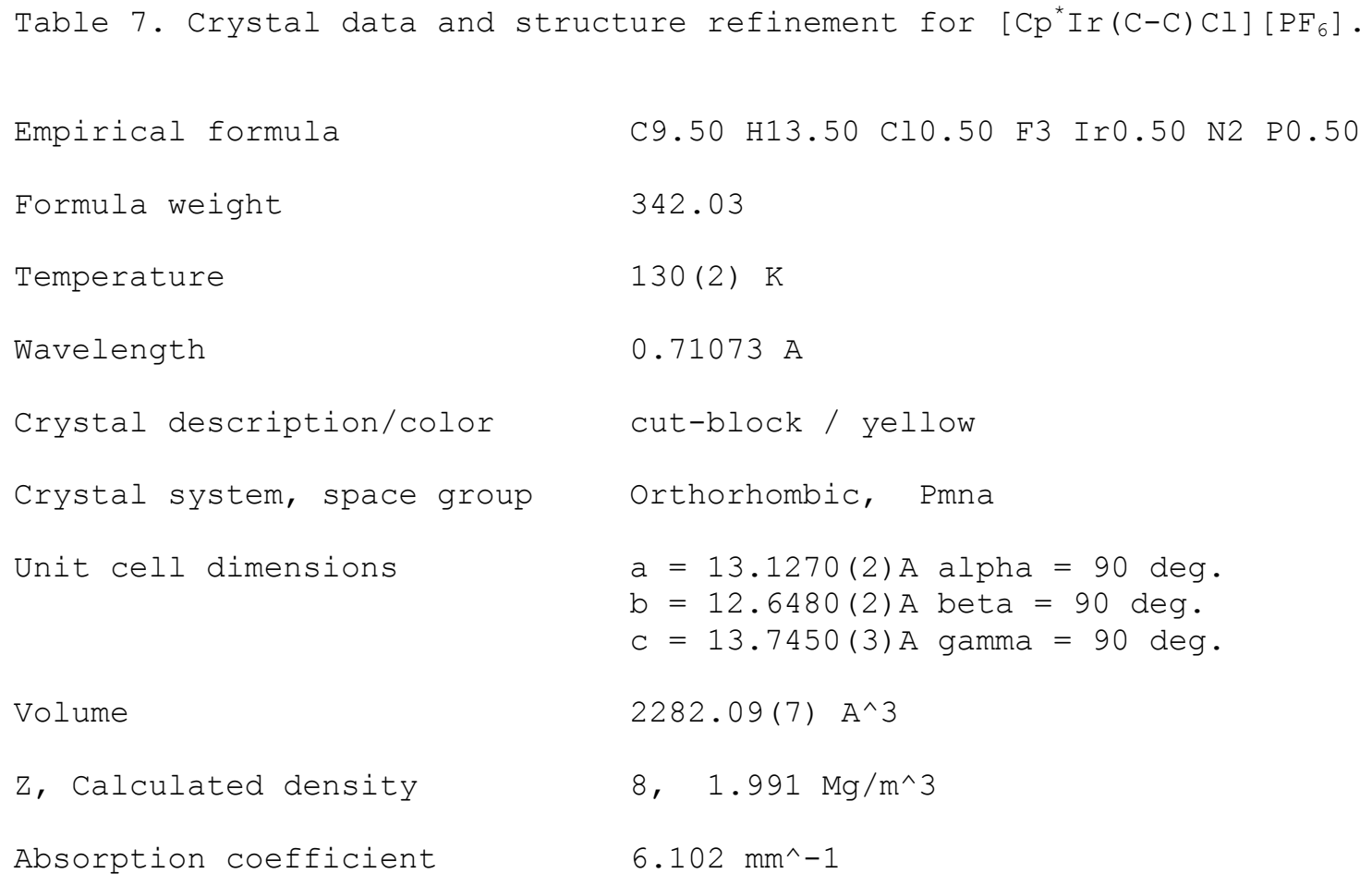

Empirical formula

Formula weight

Temperature

Wavelength

Crystal description/color

Crystal system, space group

Unit cell dimensions

Volume

Z, Calculated density

Absorption coefficient

C9.50 H13.50 C10.50 F3 Ir0.50 N2 P0.50

342.03

$130(2) \mathrm{K}$

$0.71073 \mathrm{~A}$

cut-block / yellow

Orthorhombic, Pmna

$\mathrm{a}=13.1270(2) \mathrm{A}$ alpha $=90$ deg.

$\mathrm{b}=12.6480(2) \mathrm{A}$ beta $=90$ deg.

$\mathrm{c}=13.7450$ (3) A gamma $=90$ deg.

$2282.09(7) A^{\wedge} 3$

8, $1.991 \mathrm{Mg} / \mathrm{m}^{\wedge} 3$

$6.102 \mathrm{~mm}^{\wedge}-1$ 


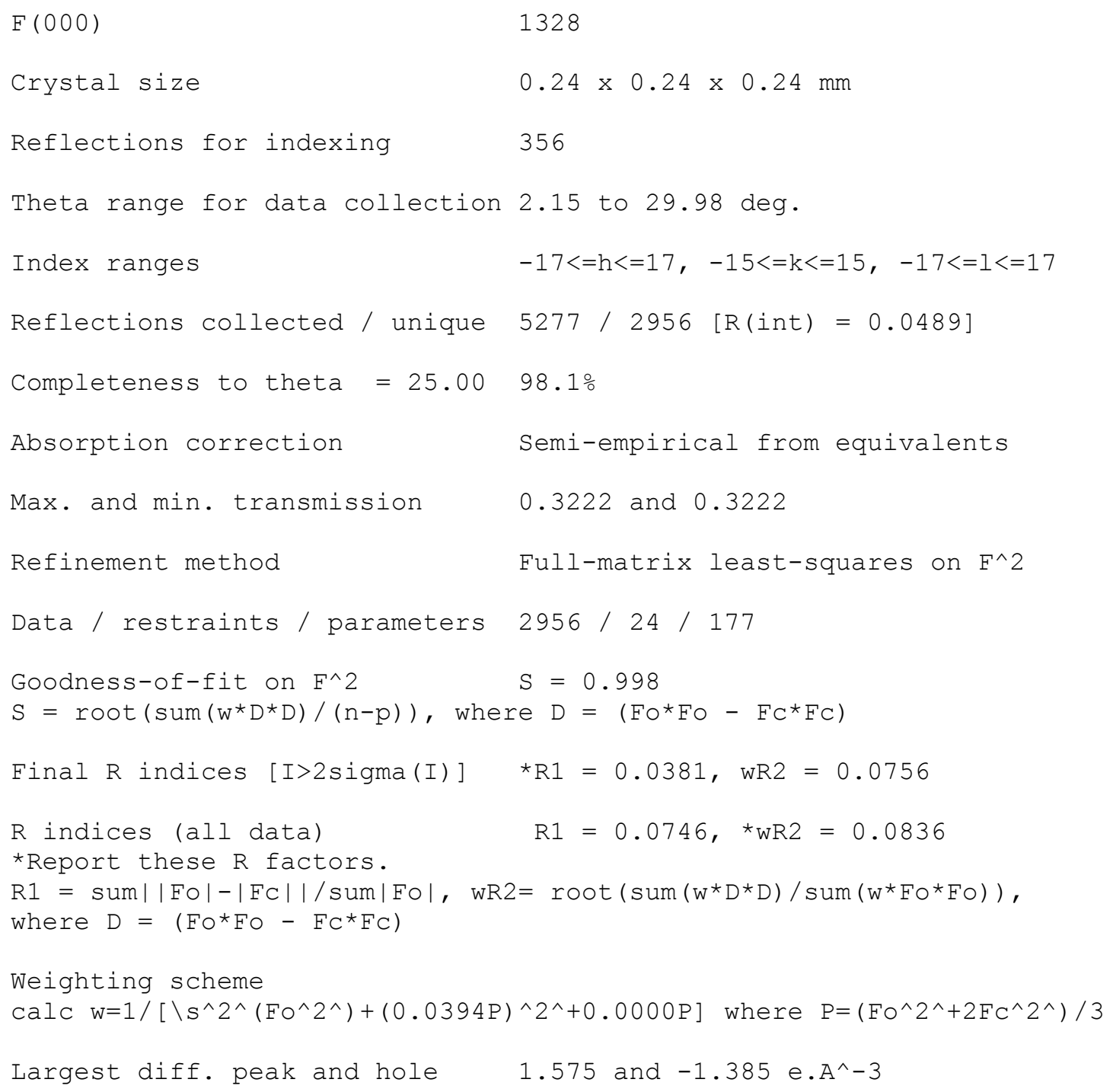


Table 8. Atomic coordinates $\left(x 1^{\wedge} 4\right)$ and equivalent isotropic displacement parameters $\left(A^{\wedge} 2 \times 10^{\wedge} 3\right)$ for shelxl.

$\mathrm{U}(\mathrm{eq})$ is defined as one third of the trace of the orthogonalized Uij tensor.

\begin{tabular}{|c|c|c|c|c|}
\hline & $x$ & $\mathrm{y}$ & z & $\mathrm{U}(\mathrm{eq})$ \\
\hline $\operatorname{Ir}(1)$ & $1196(1)$ & 7500 & $1594(1)$ & $20(1)$ \\
\hline $\mathrm{Cl}(1)$ & $2436(1)$ & 7500 & $2883(2)$ & $34(1)$ \\
\hline P (1) & $4666(2)$ & 2500 & $1773(2)$ & $34(1)$ \\
\hline $\mathrm{F}(1)$ & $5757(5)$ & 2500 & $2262(5)$ & $84(2)$ \\
\hline$F(2)$ & $3591(5)$ & 2500 & $1246(8)$ & $106(3)$ \\
\hline F (3) & $5163(10)$ & $2001(10)$ & $878(9)$ & $113(4)$ \\
\hline$F(4)$ & $4850(7)$ & $1343(7)$ & $1333(8)$ & $61(3)$ \\
\hline$F(5)$ & $4412(10)$ & 1360 & $2303(11)$ & $112(4)$ \\
\hline$F(6)$ & $4158(10)$ & 2078 & $2643(9)$ & $114(5)$ \\
\hline $\mathrm{N}(1)$ & $2341(3)$ & $5426(4)$ & $1111(4)$ & $28(1)$ \\
\hline $\mathrm{N}(2)$ & $2424(3)$ & $6561(4)$ & $-44(3)$ & $27(1)$ \\
\hline C (1) & $-312(5)$ & 7500 & $999(6)$ & $29(2)$ \\
\hline C (2) & $-257(4)$ & $6582(5)$ & $1615(4)$ & $27(1)$ \\
\hline C (3) & $-52(4)$ & $6938(5)$ & $2571(4)$ & $26(1)$ \\
\hline C (4) & $-679(7)$ & 7500 & $-48(7)$ & $52(3)$ \\
\hline$C(5)$ & $-417(5)$ & $5471(5)$ & $1273(6)$ & $48(2)$ \\
\hline$C(6)$ & $44(5)$ & $6273(5)$ & $3465(4)$ & $39(2)$ \\
\hline$C(7)$ & $2038(4)$ & $6411(4)$ & $861(4)$ & $27(1)$ \\
\hline$C(8)$ & $2909(4)$ & $4974(5)$ & $379(5)$ & $35(2)$ \\
\hline$C(9)$ & $2969(4)$ & $5679(5)$ & $-344(4)$ & $33(1)$ \\
\hline$C(10)$ & $2227(6)$ & 7500 & $-603(6)$ & $32(2)$ \\
\hline$C(11)$ & $2152(4)$ & $4911(5)$ & $2032(5)$ & $36(2)$ \\
\hline
\end{tabular}


Table 9. Bond lengths [A] and angles [deg] for shelxl.

\begin{tabular}{|c|c|}
\hline $\operatorname{Ir}(1)-C(7) \# 1$ & $2.033(5)$ \\
\hline $\operatorname{Ir}(1)-C(7)$ & $2.033(5)$ \\
\hline $\operatorname{Ir}(1)-C(1)$ & $2.141(7)$ \\
\hline $\operatorname{Ir}(1)-C(2) \# 1$ & $2.233(5)$ \\
\hline $\operatorname{Ir}(1)-C(2)$ & $2.233(5)$ \\
\hline $\operatorname{Ir}(1)-C(3) \# 1$ & $2.234(5)$ \\
\hline $\operatorname{Ir}(1)-C(3)$ & $2.234(5)$ \\
\hline $\operatorname{Ir}(1)-\operatorname{Cl}(1)$ & $2.407(2)$ \\
\hline$P(1)-F(6)$ & $1.470(10)$ \\
\hline$P(1)-F(6) \# 2$ & $1.470(10)$ \\
\hline$P(1)-F(3)$ & $1.528(11)$ \\
\hline$P(1)-F(3) \# 2$ & $1.528(11)$ \\
\hline$P(1)-F(1)$ & $1.582(7)$ \\
\hline$P(1)-F(2)$ & $1.586(7)$ \\
\hline$P(1)-F(4)$ & $1.601(8)$ \\
\hline$P(1)-F(4) \# 2$ & $1.601(8)$ \\
\hline$P(1)-F(5)$ & $1.650(7)$ \\
\hline$P(1)-F(5) \# 2$ & $1.650(7)$ \\
\hline$F(3)-F(4)$ & $1.120(14)$ \\
\hline$F(3)-F(3) \# 2$ & $1.26(3)$ \\
\hline$F(4)-F(5)$ & $1.452(16)$ \\
\hline$F(5)-F(6)$ & $1.074(10)$ \\
\hline$F(6)-F(6) \# 2$ & 1.0675 \\
\hline$N(1)-C(7)$ & $1.353(7)$ \\
\hline$N(1)-C(8)$ & $1.376(7)$ \\
\hline $\mathrm{N}(1)-\mathrm{C}(11)$ & $1.445(8)$ \\
\hline$N(2)-C(7)$ & $1.356(7)$ \\
\hline$N(2)-C(9)$ & $1.388(7)$ \\
\hline$N(2)-C(10)$ & $1.438(6)$ \\
\hline$C(1)-C(2) \# 1$ & $1.439(8)$ \\
\hline$C(1)-C(2)$ & $1.439(8)$ \\
\hline$C(1)-C(4)$ & $1.517(12)$ \\
\hline$C(2)-C(3)$ & $1.416(8)$ \\
\hline$C(2)-C(5)$ & $1.496(8)$ \\
\hline$C(3)-C(3) \# 1$ & $1.422(12)$ \\
\hline$C(3)-C(6)$ & $1.495(8)$ \\
\hline $\mathrm{C}(4)-\mathrm{H}(4 \mathrm{~A})$ & 0.9802 \\
\hline $\mathrm{C}(4)-\mathrm{H}(4 \mathrm{~B})$ & 0.9802 \\
\hline $\mathrm{C}(4)-\mathrm{H}(4 \mathrm{C})$ & 0.9802 \\
\hline $\mathrm{C}(5)-\mathrm{H}(5 \mathrm{~A})$ & 0.9800 \\
\hline$C(5)-H(5 B)$ & 0.9800 \\
\hline $\mathrm{C}(5)-\mathrm{H}(5 \mathrm{C})$ & 0.9800 \\
\hline $\mathrm{C}(6)-\mathrm{H}(6 \mathrm{~A})$ & 0.9800 \\
\hline $\mathrm{C}(6)-\mathrm{H}(6 \mathrm{~B})$ & 0.9800 \\
\hline $\mathrm{C}(6)-\mathrm{H}(6 \mathrm{C})$ & 0.9800 \\
\hline$C(8)-C(9)$ & $1.338(8)$ \\
\hline $\mathrm{C}(8)-\mathrm{H}(8)$ & 0.9500 \\
\hline $\mathrm{C}(9)-\mathrm{H}(9)$ & 0.9500 \\
\hline $\mathrm{C}(10)-\mathrm{N}(2) \# 1$ & $1.438(6)$ \\
\hline $\mathrm{C}(10)-\mathrm{H}(10 \mathrm{~A})$ & 0.9900 \\
\hline $\mathrm{C}(10)-\mathrm{H}(10 \mathrm{~B})$ & 0.9900 \\
\hline $\mathrm{C}(11)-\mathrm{H}(11 \mathrm{~A})$ & 0.9800 \\
\hline
\end{tabular}




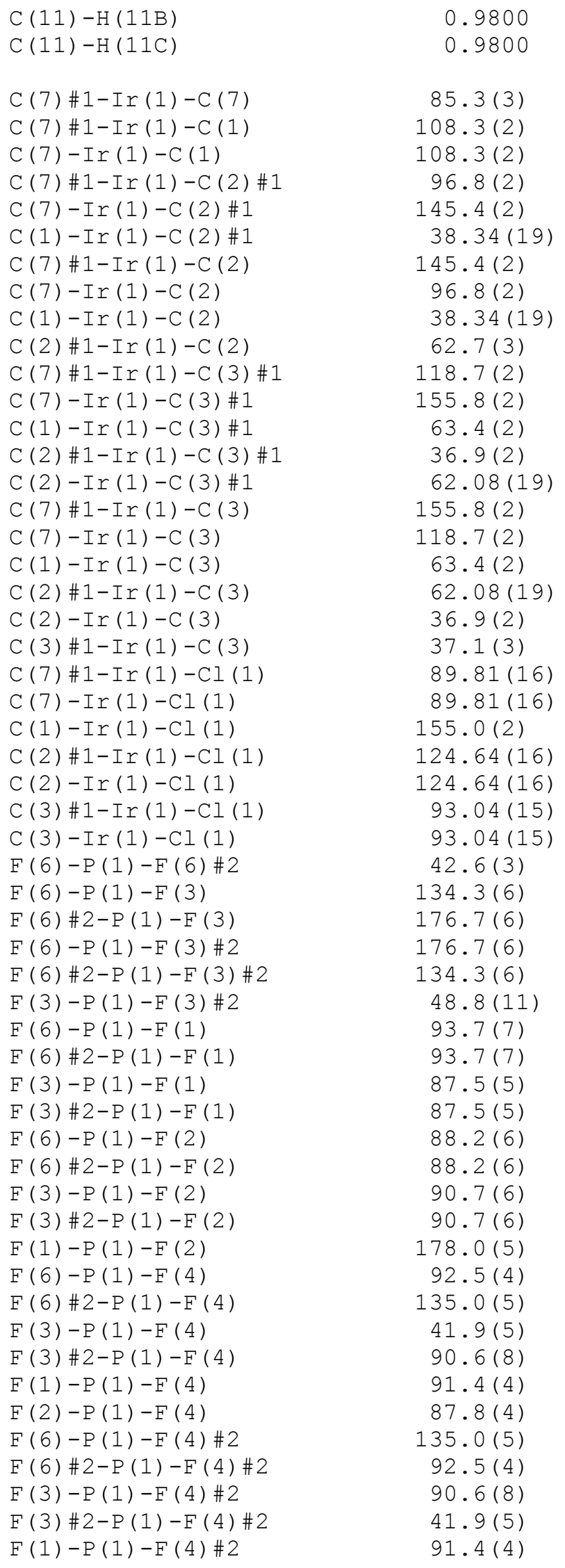




\begin{tabular}{|c|c|}
\hline$F(2)-P(1)-F(4) \# 2$ & $87.8(4)$ \\
\hline$F(4)-P(1)-F(4) \# 2$ & $132.1(8)$ \\
\hline$F(6)-P(1)-F(5)$ & $39.8(5)$ \\
\hline$F(6) \# 2-P(1)-F(5)$ & $82.3(5)$ \\
\hline$F(3)-P(1)-F(5)$ & $94.7(7)$ \\
\hline$F(3) \# 2-P(1)-F(5)$ & $143.4(7)$ \\
\hline$F(1)-P(1)-F(5)$ & $89.7(5)$ \\
\hline$F(2)-P(1)-F(5)$ & $91.3(5)$ \\
\hline $\mathrm{F}(4)-\mathrm{P}(1)-\mathrm{F}(5)$ & $53.0(5)$ \\
\hline$F(4) \# 2-P(1)-F(5)$ & $174.7(7)$ \\
\hline$F(6)-P(1)-F(5) \# 2$ & $82.3(5)$ \\
\hline$F(6) \# 2-P(1)-F(5) \# 2$ & $39.8(5)$ \\
\hline$F(3)-P(1)-F(5) \# 2$ & $143.4(8)$ \\
\hline$F(3) \# 2-P(1)-F(5) \# 2$ & $94.7(7)$ \\
\hline$F(1)-P(1)-F(5) \# 2$ & $89.7(5)$ \\
\hline$F(2)-P(1)-F(5) \# 2$ & $91.3(5)$ \\
\hline$F(4)-P(1)-F(5) \# 2$ & $174.7(7)$ \\
\hline$F(4) \# 2-P(1)-F(5) \# 2$ & $53.0(5)$ \\
\hline$F(5)-P(1)-F(5) \# 2$ & $121.8(9)$ \\
\hline$F(4)-F(3)-F(3) \# 2$ & $138.1(7)$ \\
\hline$F(4)-F(3)-P(1)$ & $72.6(8)$ \\
\hline$F(3) \# 2-F(3)-P(1)$ & $65.6(5)$ \\
\hline$F(3)-F(4)-F(5)$ & $130.3(9)$ \\
\hline$F(3)-F(4)-P(1)$ & $65.5(7)$ \\
\hline$F(5)-F(4)-P(1)$ & $65.2(3)$ \\
\hline$F(6)-F(5)-F(4)$ & $122.3(9)$ \\
\hline$F(6)-F(5)-P(1)$ & $61.1(5)$ \\
\hline$F(4)-F(5)-P(1)$ & $61.8(6)$ \\
\hline$F(6) \# 2-F(6)-F(5)$ & $147.7(9)$ \\
\hline$F(6) \# 2-F(6)-P(1)$ & $68.71(15)$ \\
\hline$F(5)-F(6)-P(1)$ & $79.2(9)$ \\
\hline$C(7)-N(1)-C(8)$ & $110.9(5)$ \\
\hline $\mathrm{C}(7)-\mathrm{N}(1)-\mathrm{C}(11)$ & $125.9(5)$ \\
\hline $\mathrm{C}(8)-\mathrm{N}(1)-\mathrm{C}(11)$ & $123.2(5)$ \\
\hline$C(7)-N(2)-C(9)$ & $110.7(5)$ \\
\hline $\mathrm{C}(7)-\mathrm{N}(2)-\mathrm{C}(10)$ & $122.5(5)$ \\
\hline$C(9)-N(2)-C(10)$ & $126.7(5)$ \\
\hline$C(2) \# 1-C(1)-C(2)$ & $107.6(7)$ \\
\hline$C(2) \# 1-C(1)-C(4)$ & $125.0(3)$ \\
\hline$C(2)-C(1)-C(4)$ & $125.0(3)$ \\
\hline$C(2) \# 1-C(1)-\operatorname{Ir}(1)$ & $74.3(4)$ \\
\hline$C(2)-C(1)-\operatorname{Ir}(1)$ & $74.3(4)$ \\
\hline$C(4)-C(1)-\operatorname{Ir}(1)$ & $131.0(6)$ \\
\hline$C(3)-C(2)-C(1)$ & $107.4(5)$ \\
\hline$C(3)-C(2)-C(5)$ & $128.1(6)$ \\
\hline$C(1)-C(2)-C(5)$ & $124.4(6)$ \\
\hline$C(3)-C(2)-\operatorname{Ir}(1)$ & $71.6(3)$ \\
\hline$C(1)-C(2)-\operatorname{Ir}(1)$ & $67.4(4)$ \\
\hline$C(5)-C(2)-\operatorname{Ir}(1)$ & $127.1(4)$ \\
\hline$C(2)-C(3)-C(3) \# 1$ & $108.5(3)$ \\
\hline$C(2)-C(3)-C(6)$ & $126.9(6)$ \\
\hline$C(3) \# 1-C(3)-C(6)$ & $124.3(4)$ \\
\hline$C(2)-C(3)-\operatorname{Ir}(1)$ & $71.5(3)$ \\
\hline$C(3) \# 1-C(3)-\operatorname{Ir}(1)$ & $71.44(15)$ \\
\hline$C(6)-C(3)-\operatorname{Ir}(1)$ & $127.7(4)$ \\
\hline $\mathrm{C}(1)-\mathrm{C}(4)-\mathrm{H}(4 \mathrm{~A})$ & 109.5 \\
\hline$C(1)-C(4)-H(4 B)$ & 109.5 \\
\hline
\end{tabular}




\begin{tabular}{|c|c|}
\hline$H(4 A)-C(4)-H(4 B)$ & 109.5 \\
\hline $\mathrm{C}(1)-\mathrm{C}(4)-\mathrm{H}(4 \mathrm{C})$ & 109.5 \\
\hline $\mathrm{H}(4 \mathrm{~A})-\mathrm{C}(4)-\mathrm{H}(4 \mathrm{C})$ & 109.5 \\
\hline $\mathrm{H}(4 \mathrm{~B})-\mathrm{C}(4)-\mathrm{H}(4 \mathrm{C})$ & 109.5 \\
\hline$C(2)-C(5)-H(5 A)$ & 109.5 \\
\hline$C(2)-C(5)-H(5 B)$ & 109.5 \\
\hline$H(5 A)-C(5)-H(5 B)$ & 109.5 \\
\hline$C(2)-C(5)-H(5 C)$ & 109.5 \\
\hline $\mathrm{H}(5 \mathrm{~A})-\mathrm{C}(5)-\mathrm{H}(5 \mathrm{C})$ & 109.5 \\
\hline$H(5 B)-C(5)-H(5 C)$ & 109.5 \\
\hline$C(3)-C(6)-H(6 A)$ & 109.5 \\
\hline$C(3)-C(6)-H(6 B)$ & 109.5 \\
\hline $\mathrm{H}(6 \mathrm{~A})-\mathrm{C}(6)-\mathrm{H}(6 \mathrm{~B})$ & 109.5 \\
\hline$C(3)-C(6)-H(6 C)$ & 109.5 \\
\hline $\mathrm{H}(6 \mathrm{~A})-\mathrm{C}(6)-\mathrm{H}(6 \mathrm{C})$ & 109.5 \\
\hline $\mathrm{H}(6 \mathrm{~B})-\mathrm{C}(6)-\mathrm{H}(6 \mathrm{C})$ & 109.5 \\
\hline $\mathrm{N}(1)-\mathrm{C}(7)-\mathrm{N}(2)$ & $104.6(5)$ \\
\hline$N(1)-C(7)-\operatorname{Ir}(1)$ & $131.2(4)$ \\
\hline$N(2)-C(7)-\operatorname{Ir}(1)$ & $124.3(4)$ \\
\hline $\mathrm{C}(9)-\mathrm{C}(8)-\mathrm{N}(1)$ & $107.4(5)$ \\
\hline $\mathrm{C}(9)-\mathrm{C}(8)-\mathrm{H}(8)$ & 126.3 \\
\hline $\mathrm{N}(1)-\mathrm{C}(8)-\mathrm{H}(8)$ & 126.3 \\
\hline $\mathrm{C}(8)-\mathrm{C}(9)-\mathrm{N}(2)$ & $106.5(5)$ \\
\hline $\mathrm{C}(8)-\mathrm{C}(9)-\mathrm{H}(9)$ & 126.7 \\
\hline $\mathrm{N}(2)-\mathrm{C}(9)-\mathrm{H}(9)$ & 126.7 \\
\hline $\mathrm{N}(2)-\mathrm{C}(10)-\mathrm{N}(2) \# 1$ & $111.4(6)$ \\
\hline $\mathrm{N}(2)-\mathrm{C}(10)-\mathrm{H}(10 \mathrm{~A})$ & 109.4 \\
\hline $\mathrm{N}(2) \# 1-\mathrm{C}(10)-\mathrm{H}(10 \mathrm{~A})$ & 109.4 \\
\hline $\mathrm{N}(2)-\mathrm{C}(10)-\mathrm{H}(10 \mathrm{~B})$ & 109.4 \\
\hline $\mathrm{N}(2) \# 1-\mathrm{C}(10)-\mathrm{H}(10 \mathrm{~B})$ & 109.4 \\
\hline $\mathrm{H}(10 \mathrm{~A})-\mathrm{C}(10)-\mathrm{H}(10 \mathrm{~B})$ & 108.0 \\
\hline $\mathrm{N}(1)-\mathrm{C}(11)-\mathrm{H}(11 \mathrm{~A})$ & 109.5 \\
\hline $\mathrm{N}(1)-\mathrm{C}(11)-\mathrm{H}(11 \mathrm{~B})$ & 109.5 \\
\hline $\mathrm{H}(11 \mathrm{~A})-\mathrm{C}(11)-\mathrm{H}(11 \mathrm{~B})$ & 109.5 \\
\hline $\mathrm{N}(1)-\mathrm{C}(11)-\mathrm{H}(11 \mathrm{C})$ & 109.5 \\
\hline $\mathrm{H}(11 \mathrm{~A})-\mathrm{C}(11)-\mathrm{H}(11 \mathrm{C})$ & 109.5 \\
\hline $\mathrm{H}(11 \mathrm{~B})-\mathrm{C}(11)-\mathrm{H}(11 \mathrm{C})$ & 109.5 \\
\hline
\end{tabular}

Symmetry transformations used to generate equivalent atoms:

$\# 1 \quad x,-y+3 / 2, z \quad \# 2 x,-y+1 / 2, z$ 
Table 10. Anisotropic displacement parameters ( $A^{\wedge} 2 \times 10^{\wedge} 3$ ) for shelxl. The anisotropic displacement factor exponent takes the form:

$-2 \mathrm{pi}^{\wedge} 2\left[\mathrm{~h}^{\wedge} 2 \mathrm{a}^{\star \wedge} 2 \mathrm{U11}+\ldots+2 \mathrm{~h} \mathrm{k} \mathrm{a}^{\star} \mathrm{b}^{\star} \mathrm{U} 12\right.$ ]

\begin{tabular}{|c|c|c|c|c|c|c|}
\hline & U11 & $\mathrm{U} 22$ & U33 & U23 & U13 & $\mathrm{U} 12$ \\
\hline $\operatorname{Ir}(1)$ & $16(1)$ & $25(1)$ & $21(1)$ & 0 & $2(1)$ & 0 \\
\hline $\mathrm{Cl}(1)$ & $21(1)$ & $49(1)$ & $33(1)$ & 0 & $-4(1)$ & 0 \\
\hline P (1) & $33(1)$ & $23(1)$ & $47(2)$ & 0 & $2(1)$ & 0 \\
\hline $\mathrm{F}(1)$ & $60(4)$ & $125(7)$ & $66(5)$ & 0 & $-24(4)$ & 0 \\
\hline $\mathrm{F}(2)$ & $53(4)$ & $48(4)$ & $219(10)$ & 0 & $-65(5)$ & 0 \\
\hline F (3) & $125(8)$ & $133(9)$ & $81(7)$ & $-51(6)$ & $-8(6)$ & $60(6)$ \\
\hline $\mathrm{F}(4)$ & $59(5)$ & $41(5)$ & $82(6)$ & $-31(4)$ & $4(5)$ & $12(4)$ \\
\hline F (5) & $112(7)$ & $55(6)$ & $170(9)$ & $58(6)$ & $-26(7)$ & $-21(5)$ \\
\hline$F(6)$ & $133(7)$ & $120(10)$ & $90(6)$ & $-21(6)$ & $63(6)$ & $-24(6)$ \\
\hline $\mathrm{N}(1)$ & $24(2)$ & $28(3)$ & $33(3)$ & $-2(2)$ & $2(2)$ & $4(2)$ \\
\hline $\mathrm{N}(2)$ & $22(2)$ & $34(3)$ & $24(3)$ & $-4(2)$ & $4(2)$ & $1(2)$ \\
\hline$C(1)$ & $12(4)$ & $46(5)$ & $27(5)$ & 0 & $-1(3)$ & 0 \\
\hline$C(2)$ & $13(2)$ & $36(3)$ & $33(3)$ & $-8(3)$ & $1(2)$ & $0(2)$ \\
\hline C (3) & $11(2)$ & $38(3)$ & $29(3)$ & $3(3)$ & $8(2)$ & $-1(2)$ \\
\hline$C(4)$ & $33(5)$ & $96(8)$ & $29(6)$ & 0 & $-11(4)$ & 0 \\
\hline C (5) & $38(4)$ & $36(4)$ & $69(5)$ & $-18(3)$ & $10(3)$ & $-11(3)$ \\
\hline$C(6)$ & $32(3)$ & $45(4)$ & $40(4)$ & $21(3)$ & $11(3)$ & $2(3)$ \\
\hline$C(7)$ & $22(3)$ & $29(3)$ & $30(3)$ & $2(3)$ & $1(2)$ & $3(2)$ \\
\hline$C(8)$ & $22(3)$ & $38(4)$ & $44(4)$ & $-20(3)$ & $-1(3)$ & $5(3)$ \\
\hline$C(9)$ & $24(3)$ & $44(4)$ & $31(4)$ & $-18(3)$ & $1(3)$ & $4(3)$ \\
\hline C (10) & $30(4)$ & $44(5)$ & $22(5)$ & 0 & $2(3)$ & 0 \\
\hline C (11) & 35 (3) & $39(4)$ & $35(4)$ & $12(3)$ & $1(3)$ & $8(3)$ \\
\hline
\end{tabular}




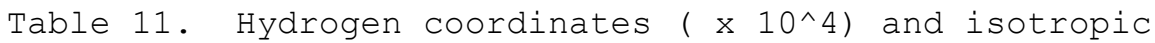
displacement parameters $\left(A^{\wedge} 2 \times 10^{\wedge} 3\right)$ for shelxl.

\begin{tabular}{lrrrr}
\hline & & & & \\
& $x$ & & & $U(e q)$ \\
\hline H (4A) & -395 & 8113 & -390 & 79 \\
H (4B) & -1424 & 7537 & -61 & 79 \\
H (4C) & -454 & 6850 & -371 & 79 \\
H (5A) & -271 & 4980 & 1806 & 72 \\
H (5B) & 40 & 5324 & 726 & 72 \\
H (5C) & -1125 & 5382 & 1062 & 72 \\
H (6A) & -523 & 6427 & 3907 & 58 \\
H (6B) & 690 & 6431 & 3792 & 58 \\
H (6C) & 28 & 5523 & 3284 & 58 \\
H (8) & 3203 & 4287 & 386 & 42 \\
H (9) & 3317 & 5593 & -945 & 39 \\
H (10A) & 1507 & 7500 & -818 & 38 \\
H (10B) & 2663 & 7500 & -1190 & 38 \\
H (11A) & 1933 & 5438 & 2512 & 55 \\
H (11B) & 2777 & 4568 & 2259 & 55 \\
H (11C) & 1616 & 4379 & 1951 & 55 \\
& & & & \\
\hline
\end{tabular}


Table 12. Torsion angles [deg] for shelxl.

\begin{tabular}{|c|c|}
\hline$F(6)-P(1)-F(3)-F(4)$ & $2.2(15)$ \\
\hline$F(6) \# 2-P(1)-F(3)-F(4)$ & $-16(13)$ \\
\hline$F(3) \# 2-P(1)-F(3)-F(4)$ & $-176.3(7)$ \\
\hline$F(1)-P(1)-F(3)-F(4)$ & $94.9(8)$ \\
\hline$F(2)-P(1)-F(3)-F(4)$ & $-85.9(8)$ \\
\hline$F(4) \# 2-P(1)-F(3)-F(4)$ & $-173.8(11)$ \\
\hline$F(5)-P(1)-F(3)-F(4)$ & $5.4(10)$ \\
\hline$F(5) \# 2-P(1)-F(3)-F(4)$ & $-179.0(9)$ \\
\hline$F(6)-P(1)-F(3)-F(3) \# 2$ & $178.4(11)$ \\
\hline$F(6) \# 2-P(1)-F(3)-F(3) \# 2$ & $160(13)$ \\
\hline$F(1)-P(1)-F(3)-F(3) \# 2$ & $-88.8(2)$ \\
\hline$F(2)-P(1)-F(3)-F(3) \# 2$ & $90.3(3)$ \\
\hline$F(4)-P(1)-F(3)-F(3) \# 2$ & $176.3(7)$ \\
\hline$F(4) \# 2-P(1)-F(3)-F(3) \# 2$ & $2.5(4)$ \\
\hline$F(5)-P(1)-F(3)-F(3) \# 2$ & $-178.4(5)$ \\
\hline$F(5) \# 2-P(1)-F(3)-F(3) \# 2$ & $-2.7(9)$ \\
\hline$F(3) \# 2-F(3)-F(4)-F(5)$ & $-13(2)$ \\
\hline$P(1)-F(3)-F(4)-F(5)$ & $-8.0(14)$ \\
\hline$F(3) \# 2-F(3)-F(4)-P(1)$ & $-5.1(9)$ \\
\hline$F(6)-P(1)-F(4)-F(3)$ & $-178.4(10)$ \\
\hline$F(6) \# 2-P(1)-F(4)-F(3)$ & $178.7(11)$ \\
\hline$F(3) \# 2-P(1)-F(4)-F(3)$ & $2.8(5)$ \\
\hline$F(1)-P(1)-F(4)-F(3)$ & $-84.7(9)$ \\
\hline$F(2)-P(1)-F(4)-F(3)$ & $93.5(9)$ \\
\hline$F(4) \# 2-P(1)-F(4)-F(3)$ & $8.4(15)$ \\
\hline$F(5)-P(1)-F(4)-F(3)$ & $-173.3(12)$ \\
\hline$F(5) \# 2-P(1)-F(4)-F(3)$ & $173(6)$ \\
\hline$F(6)-P(1)-F(4)-F(5)$ & $-5.2(9)$ \\
\hline$F(6) \# 2-P(1)-F(4)-F(5)$ & $-8.0(13)$ \\
\hline$F(3)-P(1)-F(4)-F(5)$ & $173.3(12)$ \\
\hline$F(3) \# 2-P(1)-F(4)-F(5)$ & $176.1(8)$ \\
\hline$F(1)-P(1)-F(4)-F(5)$ & $88.6(7)$ \\
\hline$F(2)-P(1)-F(4)-F(5)$ & $-93.2(7)$ \\
\hline$F(4) \# 2-P(1)-F(4)-F(5)$ & $-178.3(8)$ \\
\hline$F(5) \# 2-P(1)-F(4)-F(5)$ & $-13(6)$ \\
\hline$F(3)-F(4)-F(5)-F(6)$ & $16(3)$ \\
\hline$P(1)-F(4)-F(5)-F(6)$ & $8.4(15)$ \\
\hline$F(3)-F(4)-F(5)-P(1)$ & $8.0(14)$ \\
\hline$F(6) \# 2-P(1)-F(5)-F(6)$ & $2.4(6)$ \\
\hline$F(3)-P(1)-F(5)-F(6)$ & $-176.4(13)$ \\
\hline$F(3) \# 2-P(1)-F(5)-F(6)$ & $-178.5(12)$ \\
\hline$F(1)-P(1)-F(5)-F(6)$ & $96.2(12)$ \\
\hline$F(2)-P(1)-F(5)-F(6)$ & $-85.6(12)$ \\
\hline$F(4)-P(1)-F(5)-F(6)$ & $-171.9(15)$ \\
\hline$F(4) \# 2-P(1)-F(5)-F(6)$ & $-6(7)$ \\
\hline $\mathrm{F}(5) \# 2-\mathrm{P}(1)-\mathrm{F}(5)-\mathrm{F}(6)$ & $6.6(18)$ \\
\hline$F(6)-P(1)-F(5)-F(4)$ & $171.9(15)$ \\
\hline$F(6) \# 2-P(1)-F(5)-F(4)$ & $174.3(9)$ \\
\hline$F(3)-P(1)-F(5)-F(4)$ & $-4.5(8)$ \\
\hline$F(3) \# 2-P(1)-F(5)-F(4)$ & $-6.5(13)$ \\
\hline$F(1)-P(1)-F(5)-F(4)$ & $-91.9(6)$ \\
\hline$F(2)-P(1)-F(5)-F(4)$ & $86.3(6)$ \\
\hline$F(4) \# 2-P(1)-F(5)-F(4)$ & $166(6)$ \\
\hline
\end{tabular}




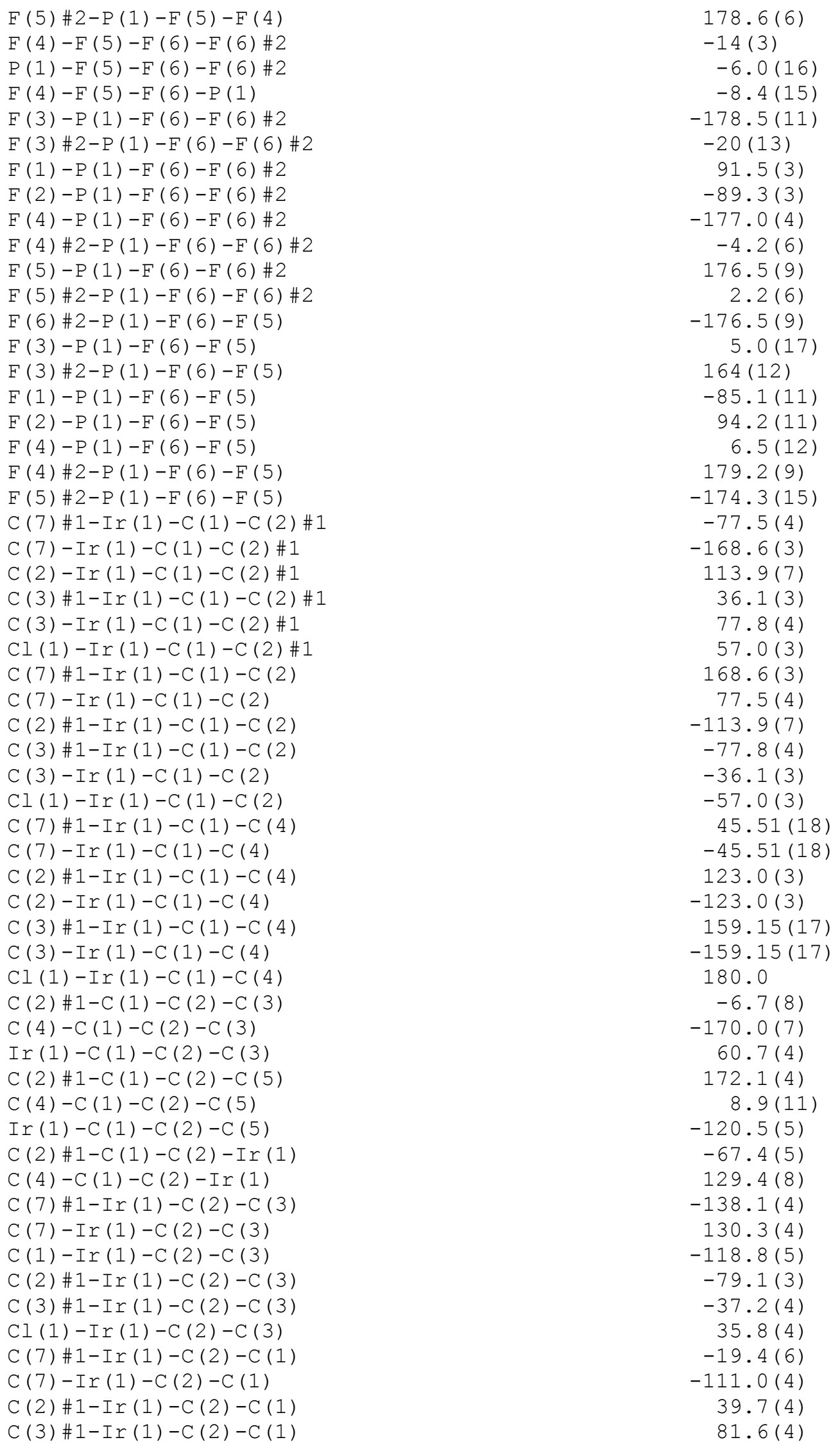




\begin{tabular}{|c|c|}
\hline$C(3)-\operatorname{Ir}(1)-C(2)-C(1)$ & $118.8(5)$ \\
\hline $\mathrm{Cl}(1)-\operatorname{Ir}(1)-\mathrm{C}(2)-\mathrm{C}(1)$ & $154.5(3)$ \\
\hline$C(7) \# 1-\operatorname{Ir}(1)-C(2)-C(5)$ & $97.6(6)$ \\
\hline$C(7)-\operatorname{Ir}(1)-C(2)-C(5)$ & $6.0(6)$ \\
\hline$C(1)-\operatorname{Ir}(1)-C(2)-C(5)$ & $116.9(7)$ \\
\hline$C(2) \# 1-\operatorname{Ir}(1)-C(2)-C(5)$ & $156.6(5)$ \\
\hline$C(3) \# 1-\operatorname{Ir}(1)-C(2)-C(5)$ & $-161.5(6)$ \\
\hline$C(3)-\operatorname{Ir}(1)-C(2)-C(5)$ & $-124.3(7)$ \\
\hline$C l(1)-\operatorname{Ir}(1)-C(2)-C(5)$ & $-88.5(6)$ \\
\hline$C(1)-C(2)-C(3)-C(3) \# 1$ & $4.2(5)$ \\
\hline$C(5)-C(2)-C(3)-C(3) \# 1$ & $-174.6(5)$ \\
\hline $\operatorname{Ir}(1)-C(2)-C(3)-C(3) \# 1$ & $62.20(14)$ \\
\hline$C(1)-C(2)-C(3)-C(6)$ & $178.2(5)$ \\
\hline$C(5)-C(2)-C(3)-C(6)$ & $-0.6(9)$ \\
\hline $\operatorname{Ir}(1)-C(2)-C(3)-C(6)$ & $-123.8(5)$ \\
\hline$C(1)-C(2)-C(3)-\operatorname{Ir}(1)$ & $-58.0(4)$ \\
\hline$C(5)-C(2)-C(3)-\operatorname{Ir}(1)$ & $123.2(6)$ \\
\hline$C(7) \# 1-\operatorname{Ir}(1)-C(3)-C(2)$ & $112.5(6)$ \\
\hline$C(7)-\operatorname{Ir}(1)-C(3)-C(2)$ & $-59.7(4)$ \\
\hline$C(1)-\operatorname{Ir}(1)-C(3)-C(2)$ & $37.5(3)$ \\
\hline$C(2) \# 1-\operatorname{Ir}(1)-C(3)-C(2)$ & $80.8(4)$ \\
\hline$C(3) \# 1-\operatorname{Ir}(1)-C(3)-C(2)$ & $117.8(3)$ \\
\hline $\mathrm{Cl}(1)-\operatorname{Ir}(1)-\mathrm{C}(3)-\mathrm{C}(2)$ & $-151.2(3)$ \\
\hline$C(7) \# 1-\operatorname{Ir}(1)-C(3)-C(3) \# 1$ & $-5.3(5)$ \\
\hline$C(7)-\operatorname{Ir}(1)-C(3)-C(3) \# 1$ & $-177.5(2)$ \\
\hline$C(1)-\operatorname{Ir}(1)-C(3)-C(3) \# 1$ & $-80.33(13)$ \\
\hline$C(2) \# 1-\operatorname{Ir}(1)-C(3)-C(3) \# 1$ & $-37.0(2)$ \\
\hline$C(2)-\operatorname{Ir}(1)-C(3)-C(3) \# 1$ & $-117.8(3)$ \\
\hline $\mathrm{Cl}(1)-\operatorname{Ir}(1)-\mathrm{C}(3)-\mathrm{C}(3) \# 1$ & $91.02(5)$ \\
\hline$C(7) \# 1-\operatorname{Ir}(1)-C(3)-C(6)$ & $-124.7(6)$ \\
\hline$C(7)-\operatorname{Ir}(1)-C(3)-C(6)$ & $63.1(6)$ \\
\hline$C(1)-\operatorname{Ir}(1)-C(3)-C(6)$ & $160.3(6)$ \\
\hline$C(2) \# 1-\operatorname{Ir}(1)-C(3)-C(6)$ & $-156.4(6)$ \\
\hline$C(2)-\operatorname{Ir}(1)-C(3)-C(6)$ & $122.8(7)$ \\
\hline$C(3) \# 1-\operatorname{Ir}(1)-C(3)-C(6)$ & $-119.4(5)$ \\
\hline$C l(1)-\operatorname{Ir}(1)-C(3)-C(6)$ & $-28.4(5)$ \\
\hline $\mathrm{C}(8)-\mathrm{N}(1)-\mathrm{C}(7)-\mathrm{N}(2)$ & $0.3(6)$ \\
\hline $\mathrm{C}(11)-\mathrm{N}(1)-\mathrm{C}(7)-\mathrm{N}(2)$ & $177.5(5)$ \\
\hline$C(8)-N(1)-C(7)-\operatorname{Ir}(1)$ & $-179.9(4)$ \\
\hline $\mathrm{C}(11)-\mathrm{N}(1)-\mathrm{C}(7)-\operatorname{Ir}(1)$ & $-2.6(8)$ \\
\hline $\mathrm{C}(9)-\mathrm{N}(2)-\mathrm{C}(7)-\mathrm{N}(1)$ & $-0.6(6)$ \\
\hline$C(10)-N(2)-C(7)-N(1)$ & $176.5(5)$ \\
\hline$C(9)-N(2)-C(7)-\operatorname{Ir}(1)$ & $179.6(4)$ \\
\hline$C(10)-N(2)-C(7)-\operatorname{Ir}(1)$ & $-3.4(8)$ \\
\hline $\mathrm{C}(7) \# 1-\operatorname{Ir}(1)-\mathrm{C}(7)-\mathrm{N}(1)$ & $149.1(4)$ \\
\hline $\mathrm{C}(1)-\operatorname{Ir}(1)-\mathrm{C}(7)-\mathrm{N}(1)$ & $-103.2(5)$ \\
\hline $\mathrm{C}(2) \# 1-\operatorname{Ir}(1)-\mathrm{C}(7)-\mathrm{N}(1)$ & $-115.7(5)$ \\
\hline$C(2)-\operatorname{Ir}(1)-C(7)-N(1)$ & $-65.6(5)$ \\
\hline $\mathrm{C}(3) \# 1-\operatorname{Ir}(1)-\mathrm{C}(7)-\mathrm{N}(1)$ & $-37.7(9)$ \\
\hline$C(3)-\operatorname{Ir}(1)-C(7)-N(1)$ & $-34.1(6)$ \\
\hline $\mathrm{Cl}(1)-\operatorname{Ir}(1)-\mathrm{C}(7)-\mathrm{N}(1)$ & $59.3(5)$ \\
\hline $\mathrm{C}(7) \# 1-\operatorname{Ir}(1)-\mathrm{C}(7)-\mathrm{N}(2)$ & $-31.0(6)$ \\
\hline $\mathrm{C}(1)-\operatorname{Ir}(1)-\mathrm{C}(7)-\mathrm{N}(2)$ & $76.7(5)$ \\
\hline $\mathrm{C}(2) \# 1-\operatorname{Ir}(1)-\mathrm{C}(7)-\mathrm{N}(2)$ & $64.1(6)$ \\
\hline $\mathrm{C}(2)-\operatorname{Ir}(1)-\mathrm{C}(7)-\mathrm{N}(2)$ & $114.3(5)$ \\
\hline $\mathrm{C}(3) \# 1-\operatorname{Ir}(1)-\mathrm{C}(7)-\mathrm{N}(2)$ & $142.1(5)$ \\
\hline$C(3)-\operatorname{Ir}(1)-C(7)-N(2)$ & $145.8(4)$ \\
\hline
\end{tabular}


$\mathrm{Cl}(1)-\operatorname{Ir}(1)-\mathrm{C}(7)-\mathrm{N}(2)$

$\mathrm{C}(7)-\mathrm{N}(1)-\mathrm{C}(8)-\mathrm{C}(9)$

$\mathrm{C}(11)-\mathrm{N}(1)-\mathrm{C}(8)-\mathrm{C}(9)$

$\mathrm{N}(1)-\mathrm{C}(8)-\mathrm{C}(9)-\mathrm{N}(2)$

$\mathrm{C}(7)-\mathrm{N}(2)-\mathrm{C}(9)-\mathrm{C}(8)$

$\mathrm{C}(10)-\mathrm{N}(2)-\mathrm{C}(9)-\mathrm{C}(8)$

$\mathrm{C}(7)-\mathrm{N}(2)-\mathrm{C}(10)-\mathrm{N}(2) \# 1$

$\mathrm{C}(9)-\mathrm{N}(2)-\mathrm{C}(10)-\mathrm{N}(2) \# 1$
$-120.9(4)$

$0.1(6)$

$-177.2(5)$

$-0.5(6)$

$0.7(6)$

$-176.2(5)$

$50.2(9)$

$-133.3(5)$

Symmetry transformations used to generate equivalent atoms:

$\# 1 x,-y+3 / 2, z \quad \# 2 x,-y+1 / 2, z$ 
